\title{
Fabricated $\mathrm{CeO}_{2}$ nanopowders as a novel sensing platform for advanced forensic, electrochemical and photocatalytic applications
}

\author{
B. S. Rohini ${ }^{1} \cdot$ H. Nagabhushana ${ }^{1}$ - G. P. Darshan ${ }^{2}$ - R. B. Basavaraj ${ }^{1}$ \\ S. C. Sharma ${ }^{3,4} \cdot$ R. Sudarmani ${ }^{5}$
}

Received: 17 August 2017 / Accepted: 26 September 2017/Published online: 25 October 2017

(C) The Author(s) 2017. This article is an open access publication

\begin{abstract}
In Forensic investigation, identification of various types of ridge details are essential in order to fix the criminals associated in various crimes. Even though several methods and labeling agents are available to visualize latent finger prints (LFPs) there is still simple, accurate, cost-effective, and non-destructive tool is required. In the present work, $\mathrm{CeO}_{2}$ nanopowders (NPs) are prepared via simple solution combustion route using Tamarindus indica fruit extract as a fuel. The optimized NPs are utilized for visualization of LFPs on various surfaces by powder dusting method. Results revealed that visualized LFPs exhibit Level 3 features such as pores and ridge contours under normal light with high sensitivity and without background hindrance. The photometric characteristics of the prepared samples exhibit blue color emission and highly useful in warm light emitting diodes. The photocatalytic studies were carried out with different Methylene blue (MB) dye concentration and $\mathrm{pH}$ values. The obtained results reveal that the $\mathrm{CeO}_{2}$ NPs exhibits an excellent
\end{abstract}

G. P. Darshan

darshubavimane@gmail.com

1 Prof. C.N.R. Rao Centre for Advanced Materials Research, Tumkur University, Tumkur 572 103, India

2 Department of Physics, Acharya Institute of Graduate Studies, Bangalore 560 107, India

3 Avinashilingam Institute for Home Science and Higher Education for Women University, Coimbatore 641 043, India

4 Department of Mechanical Engineering, Jain Group of Institutions, Jain University, Bangalore 560 069, India

5 Department of Electronics and Communication, Avinashilingam Institute for Home Science and Higher Education for Women University, Coimbatore 641 043, India catalytic properties which can act as a good catalytic reagent. The findings demonstrate that the prepared NPs are quite useful as a labeling agent for visualization of LFPs, efficient catalysts for dye degradation as well as solid-state lighting applications.

Keywords Tamarindus indica $\cdot$ Latent fingerprints · Solution combustion route Photoluminescence . Photocatalytic activity

\section{Introduction}

Fingerprints (FPs) have provided a vital source of forensic evidence for human identification and individualization. The patterns on the FPs are individual to each person and remain same throughout lifespan. Normally most of FPs seen in the daily life is latent and invisible to naked eyes; as a result, some certain methods are necessary to recognize personal identification in forensic science. Till date numerous methods (chemical, optical) have been established to recognize LFPs. However, the recognition was restricted only level 1 and level 2 ridge details due to the poor image qualities (Saif et al. 2015; Sharma et al. 2014; Wang et al. 2015a, b, c).

Further, the level 1 and 2 features are easily forged, by the generation and use of artificial skin imprints. However, the analysis of level 3 features required some efficient nano powders with uniform particle size and morphology (Basavaraj et al. 2017; Dhanalakshmi et al. 2017; Venkatachalaiah et al. 2017). Hence, there is an urgent need to progress a simple and efficient route in developing LFPs with superior sensitivity, little background, extraordinary efficiency, lesser toxicity and stress-free detection of LFPs, which is the essential requirement for forensic 


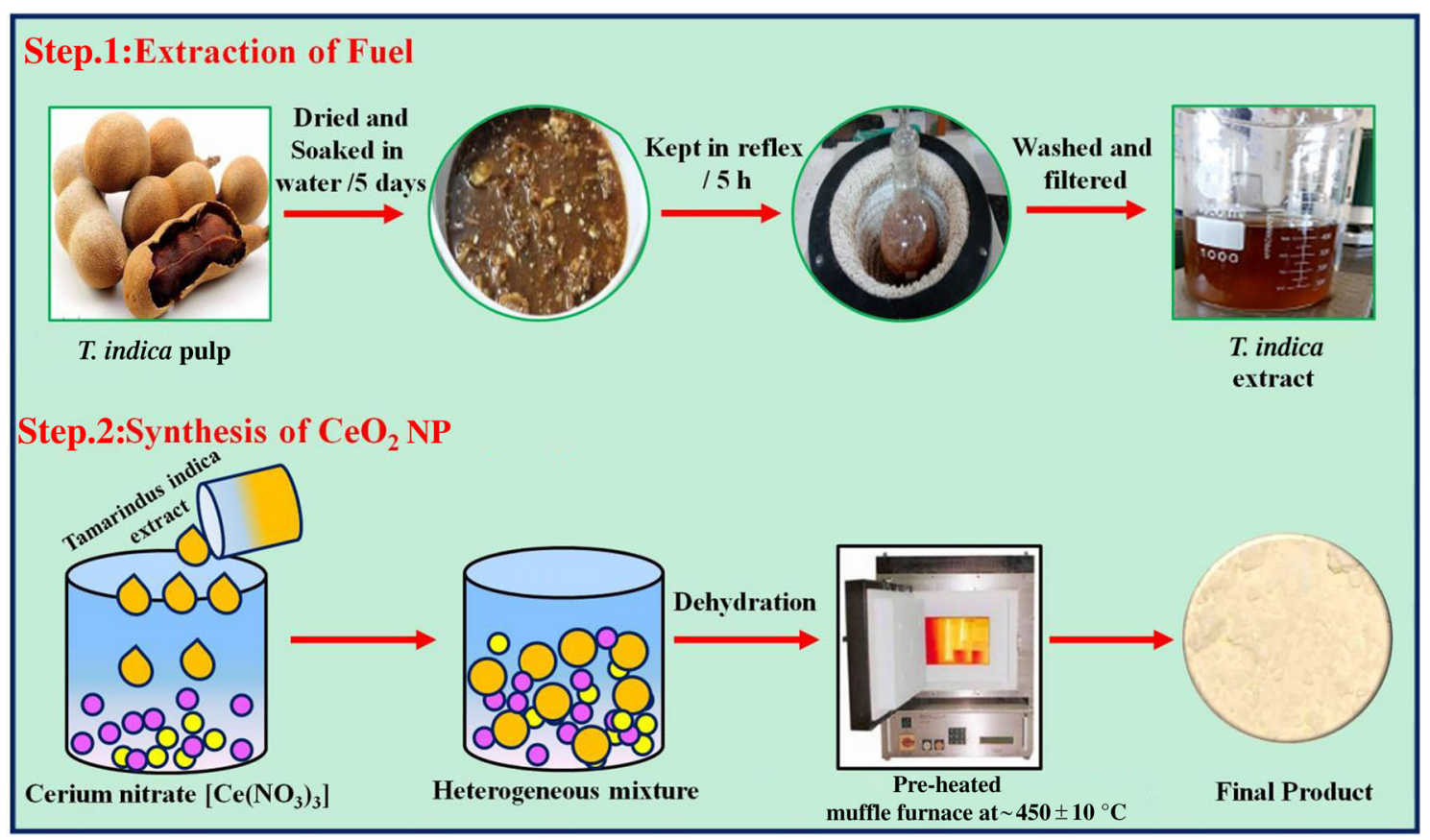

Fig. 1 Schematic representation to show various steps involved in extraction of fuel and synthesis of $\mathrm{CeO}_{2}$ NPs by solution combustion route

investigators. Further, most of the available literature for the detection of LFPs is due to excited ultraviolet (UV) radiation; rare earth doped fluorescent nanopowders can enhance FPs contrast. Conversely, UV light has many drawbacks including high background interference owing to the significant auto-fluorescence from the substrates, photo damage to the skin and eyes of the operators, and the possibility of severe irradiation-induced damage. Therefore, NPs are highly essential for the recognition of level 3 ridge details under normal light in the field of forensic science (Darshan et al. 2016; Suresh et al. 2017).

In recent years, the change in physiochemical properties of bulk material to corresponding nano regime has created numerous interest for material scientists. Due to its versatile applications in gas sensors, fuel cells, solar cells and very good photocatalytic activity, Cerium oxide nanoparticles have attracted much attention in recent years (Choi et al. 2006; Lehnen et al. 2014; Liu et al. 2013; Sathyamurthy et al. 2005; Sun et al. 2005). Its diverse applications is due to the efficiency of transfer of elevated oxygen from reduced to oxidized state (Lin et al. 2013; Zhou and Rahaman 1997). Till date, various reports of $\mathrm{CeO}_{2}$ synthesis routes are available in the literatures. In the recent years, bio-synthesis route using plant extracts is found to be environmental friendly, novel and inexpensive. Further, it does not require high pressure and high temperature (Derakhshandeh and Soleimannejad 2016; Huang et al. 2005; Maensiri et al. 2014; Maensiri et al. 2007; Wang et al. 2010). With no $4 f$ electron $\mathrm{CeO}_{2}$ would be a good host material for photoluminescent materials (Jamshidi et al. 2013; Weber 1973). Ling Li et al. reported violet/blue emission of cerium composited with silicon for its good compatibility with the silicon-based materials used in the fabrication of optoelectronics devices ( $\mathrm{Li}$ et al. 2015; Arumugam et al. 2015; Ketzial and Nesaraj 2011; Malleshappa et al. 2015; Lee et al. 2014; Lopez and Mendoza 2013).

Till date, limited reports are available for the synthesis of $\mathrm{CeO}_{2}$ NPs by solution combustion method using $\mathrm{Ta}$ marindus indica fruit extract as fuel. Further, the optimized product is utilized for visualization of LFPs on both porous and non-porous surfaces. Finally, the photocatalytic degradation is examined using MB as a dye. The detailed investigation on the mechanism related to the photocatalytic degradation is discussed.

\section{Experimental}

\section{Fruit extract}

Tamarindus indica fruit is collected from the local market of Tumkur and dried for about 5 days under the sunlight. $100 \mathrm{~g}$ of $T$. indica fruit was soaked in water for $\sim 16 \mathrm{~h}$. The obtained solution is kept in reflex for $\sim 5 \mathrm{~h}$ and then washed several times with distilled water and filtered. Finally, the obtained $T$. indica fruit extract was stored in refrigerator until further use. 
Fig. 2 a-f LFPs visualized by staining calcined $\mathrm{CeO}_{2}(15 \mathrm{ml})$ NPs on various non-porous surfaces and $\left(\mathbf{a}^{*}, \mathbf{b}^{*}, \mathbf{b}^{\mathbf{1}^{*}}, \mathbf{b}^{\mathbf{2}^{*}}, \mathbf{c}^{*}\right.$, $\mathbf{d}^{*}, \mathbf{e}^{*}$ and $\mathbf{f}^{\mathbf{1}^{*}}, \mathbf{f}^{\mathbf{2}^{*}}$ ) shows the enlarged views of FPs which exhibits various ridge prints
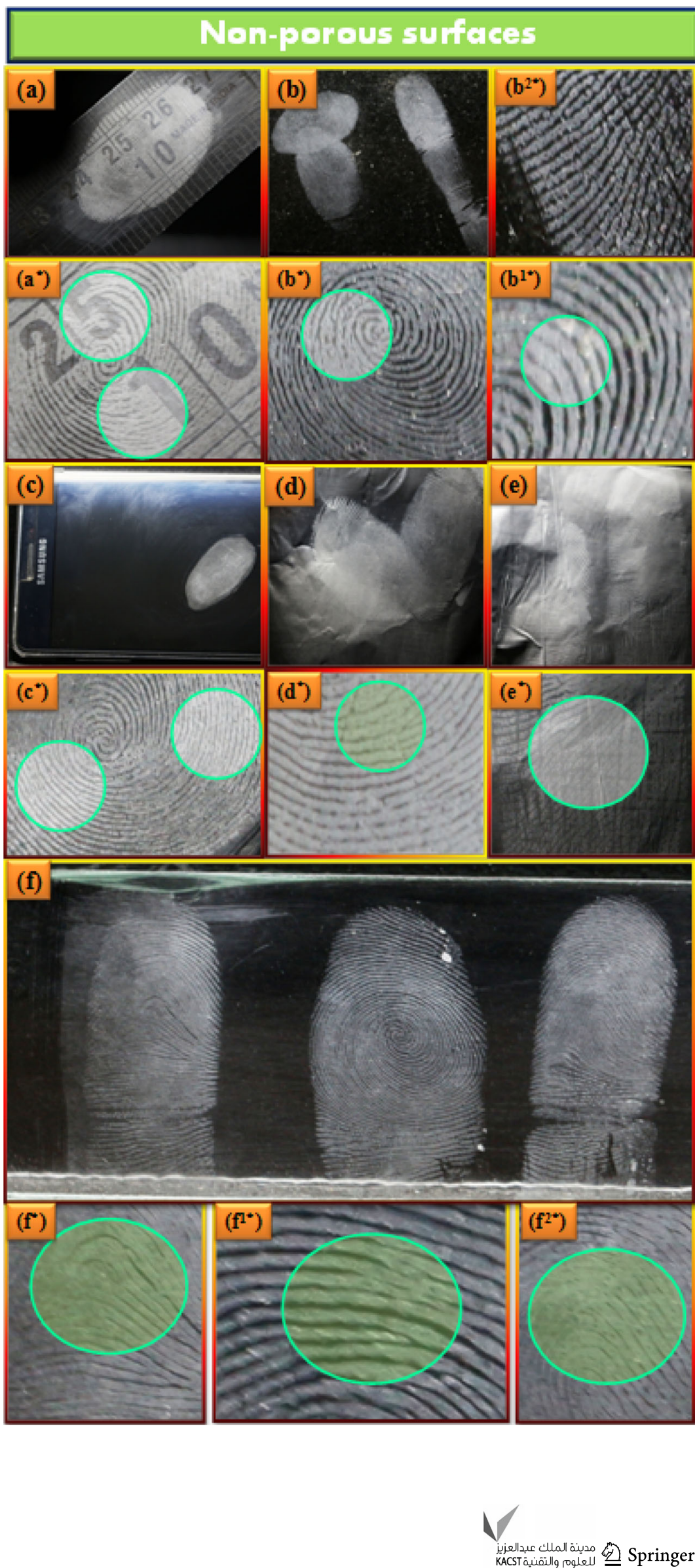

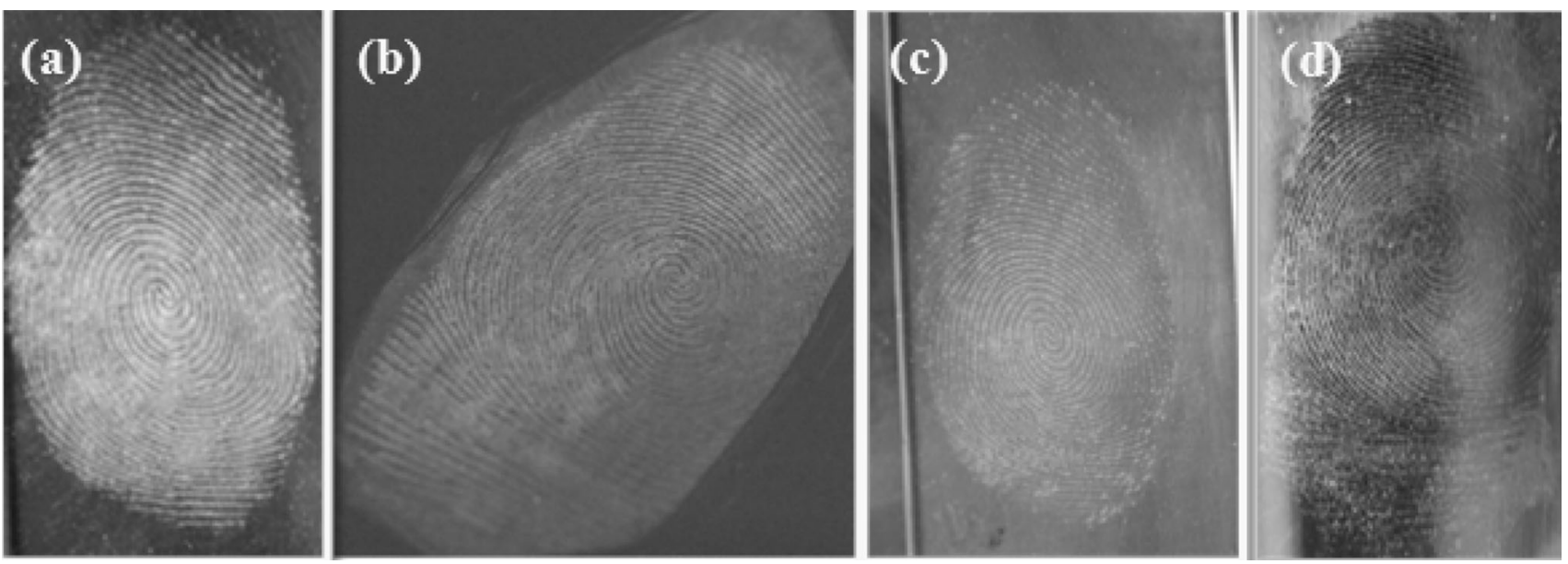

Fig. 3 LFPs aged on the surface of glass for various periods of time, stained by calcined $\mathrm{CeO}_{2}(15 \mathrm{ml})$ NPs under normal light a 1 day, b 1 week, c 2 weeks and d 3 weeks

Fig. 4 Various ridge levels of FP patterns visualized by staining optimized calcined $\mathrm{CeO}_{2}(15 \mathrm{ml}) \mathrm{NP}$ on glass surface under normal light

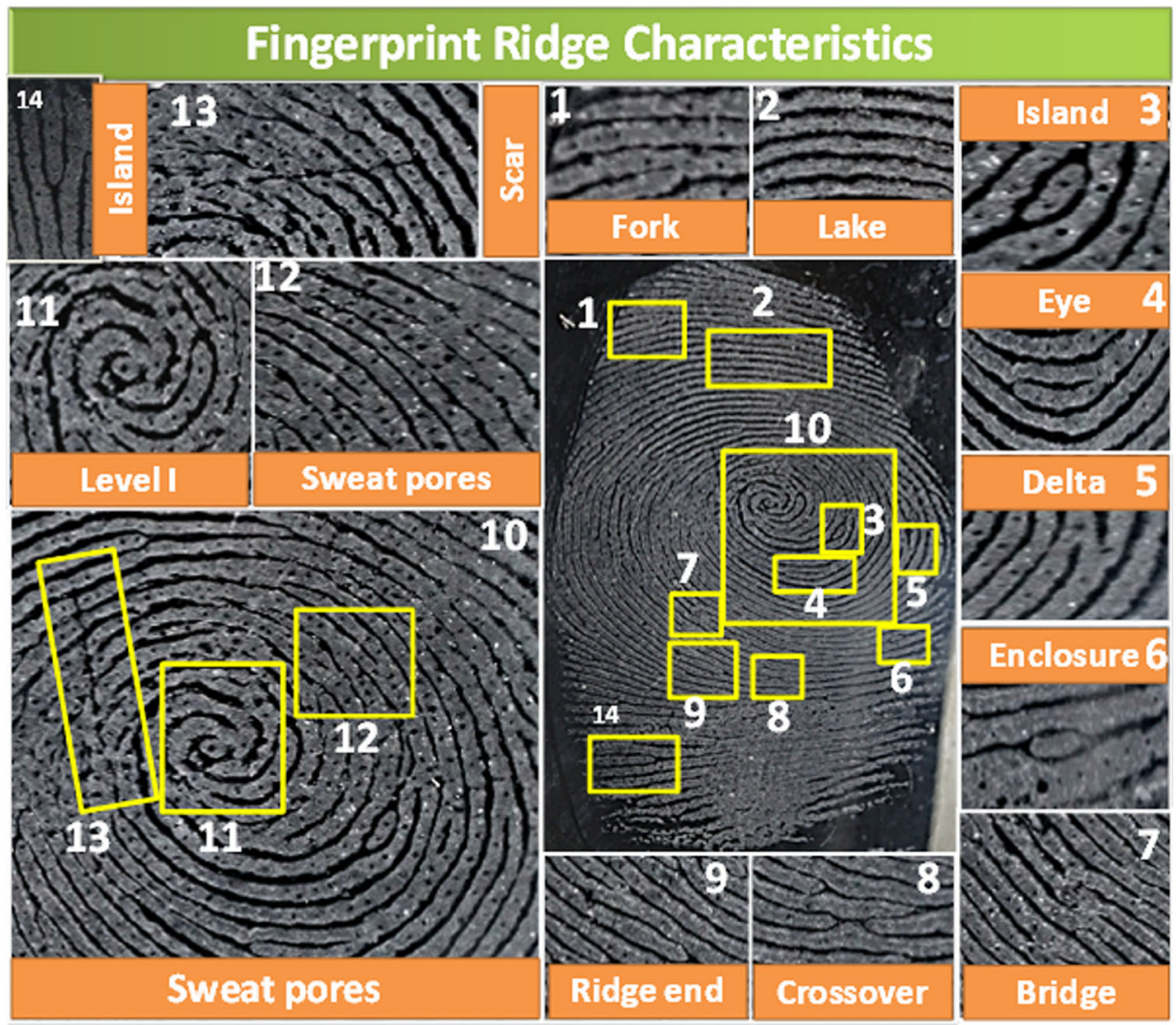

\section{Synthesis}

A simple solution combustion route is used to prepare pure $\mathrm{CeO}_{2}$ NPs using T. indica fruit extract as fuel. Initially, Cerium (III) nitrate $\left[\left(\mathrm{Ce}\left(\mathrm{NO}_{3}\right)_{3} \cdot 6 \mathrm{H}_{2} \mathrm{O}\right): 0.5 \mathrm{~g}\right]$ is taken in a petri dish and $5 \mathrm{ml}$ of $T$. indica fuel is added $(1 \mathrm{~g}$ of extract is dissolved in $250 \mathrm{ml}$ of water and stirred for $10 \mathrm{~min}$ ). The precursor solution is stirred thoroughly using magnetic stirrer $(\sim 5-10 \mathrm{~min})$ till homogeneous mixture is obtained. The resultant reaction mixture is placed in a preheated muffle furnace maintained at a temperature of $\sim 450 \pm 10^{\circ} \mathrm{C}$. The mixture undergoes dehydration with liberation of large amount of gases. Finally, a product is left behind in the petri dish. The portion of obtained 


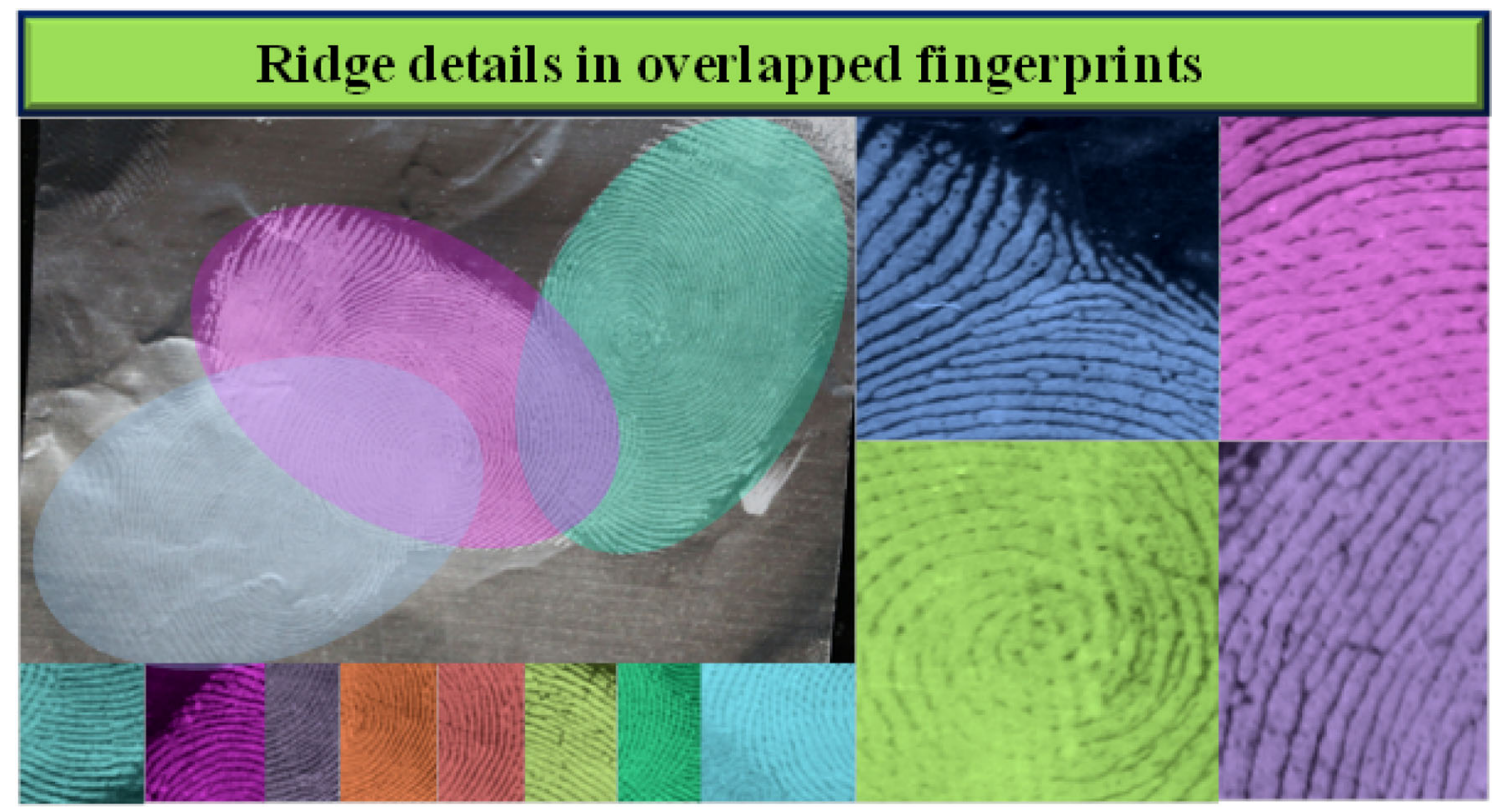

Fig. 5 Overlapped and various ridge details of FP patterns visualized using calcined $\mathrm{CeO}_{2}(15 \mathrm{ml}) \mathrm{NP}$ on aluminium foil surface
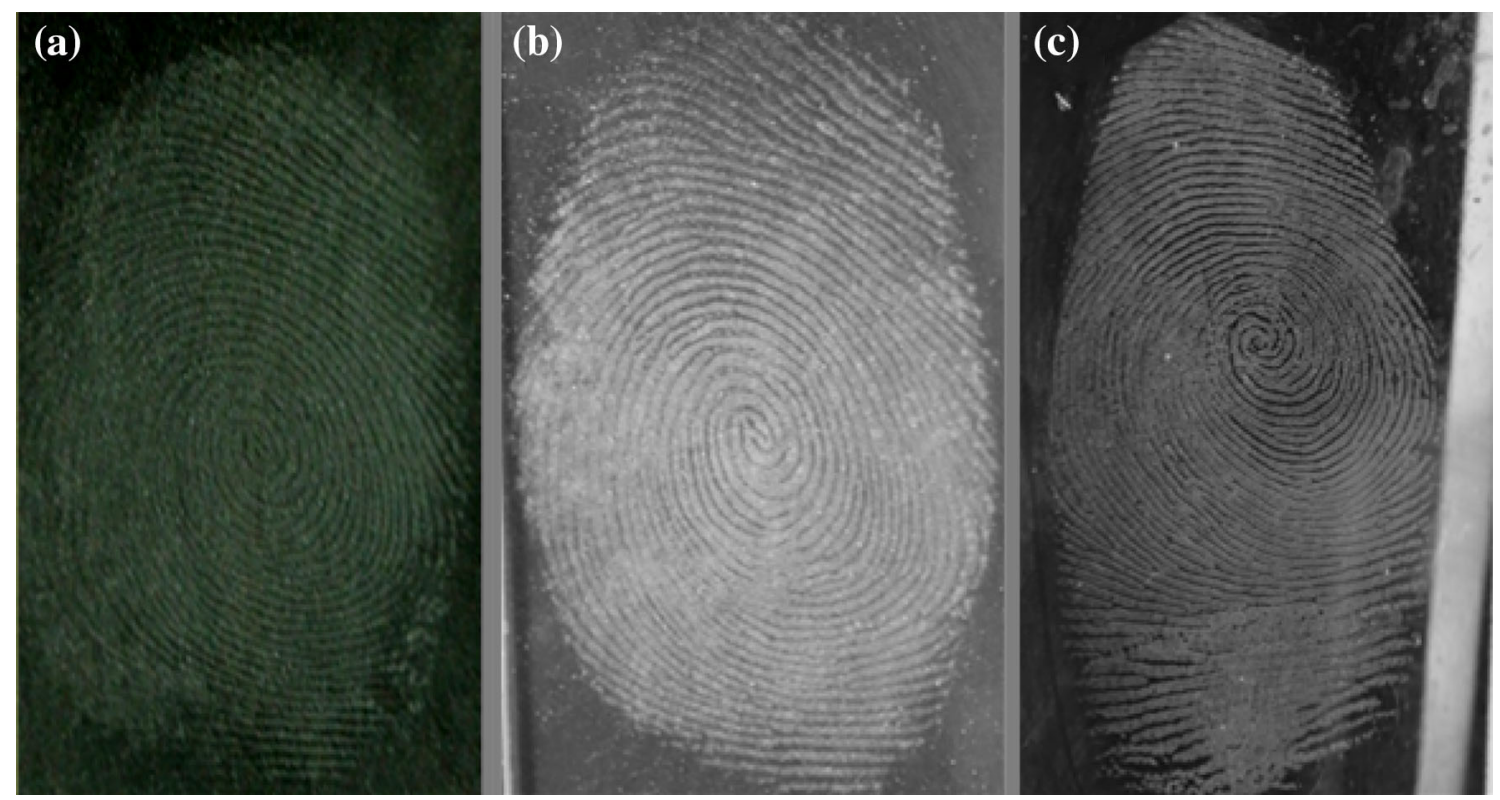

Fig. 6 Comparison of FP images visualized by staining $\mathrm{Fe}_{2} \mathrm{O}_{3}, \mathrm{TiO}_{2}$ and calcined $\mathrm{CeO}_{2}(15 \mathrm{ml}) \mathrm{NP}$ on glass surface under visible light

product is calcined at $\sim 800{ }^{\circ} \mathrm{C}$ for $3 \mathrm{~h}$. The same experimental procedure is repeated for different concentrations of $T$. indica extract $(5,10,15,20$ and $30 \mathrm{ml})$. The prepared as-formed and calcined $\mathrm{CeO}_{2} \mathrm{NPs}$ were used for further characterization. Figure 1 shows the schematic representation of the steps involved for the extraction of $T$. indica fuel and synthesis of $\mathrm{CeO}_{2} \mathrm{NPs}$.

\section{Characterization}

The powder X-ray diffraction (PXRD) measurements were performed on the Shimadzu made X-ray diffractometer (Shimadzu 7000) with graphite monochromatized $\mathrm{Cu}-\mathrm{K}_{\alpha}$ radiation $(\lambda=0.15406 \mathrm{~nm})$ to study the phase and purity of the prepared samples. The surface morphology is studied

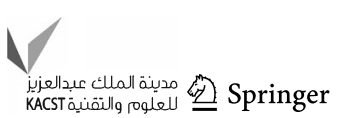


Fig. 7 PXRD patterns and $\mathrm{W}-$ $\mathrm{H}$ plots of $\mathrm{CeO}_{2}$ NPs (a, c) asformed and $(\mathbf{b}, \mathbf{d})$ calcined at $800{ }^{\circ} \mathrm{C}$

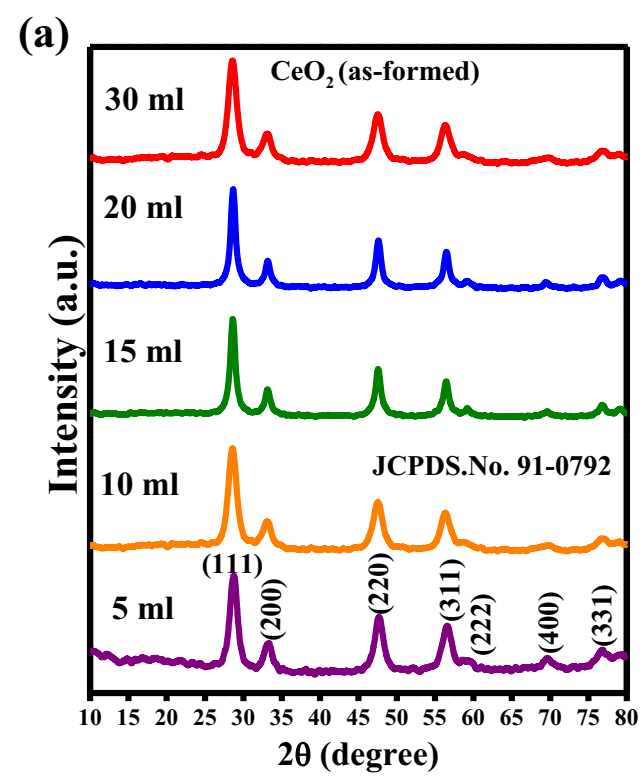

(c)

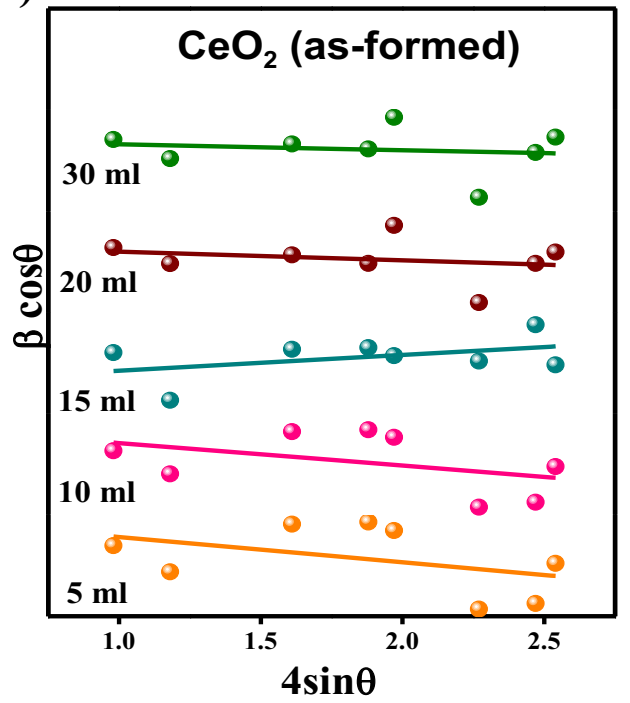

(b)

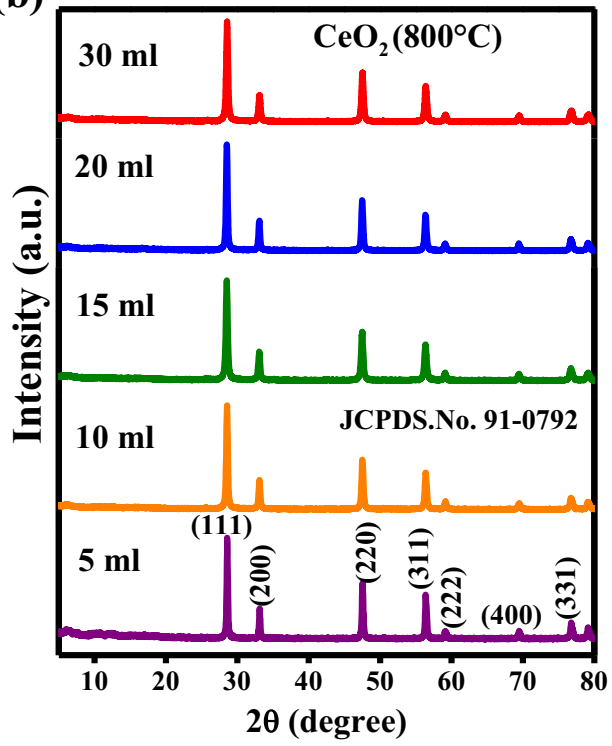

(d)

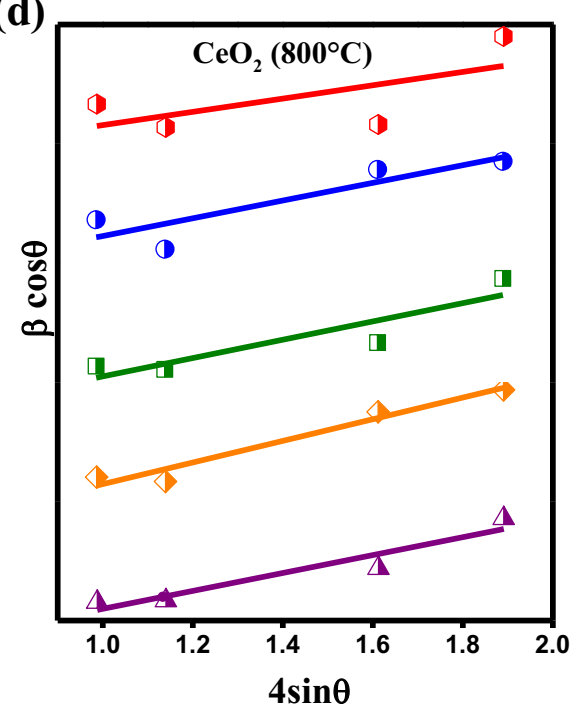

by Hitachi made table top scanning electron microscope (SEM) (Hitachi-TM 3000). Transmission electron microscope (TEM) (Hitachi H-8100, Kevex sigma TM Quasar, USA) is used to estimate the crystallite size of the material. Spectrophotometer (Lambda-35, Perkin Elmer) is used to study the diffuse reflectance of the prepared material. Spectroflourimeter equipped with Fluorolog-3 (JobinYvon) is utilized to measure the photoluminescence (PL) properties. The Fourier transform infrared (FTIR) spectrum is recorded in Bruker alpha made FTIR instrument. The Jobin-YVON Horiba LABRAM-HR-Visible micro Raman system is used for Raman studies with $\mathrm{He}-\mathrm{Ne}$ laser $(\sim 632.8 \mathrm{~nm})$ as the source.
Visualization of LFPs using $\mathrm{CeO}_{2}$ NPs as labeling agents

The LFPs are collected from healthy donor on various surfaces including porous and non-porous surfaces. The hands of the donor are washed thoroughly with soap and dried before impression. Subsequently, the washed fingers are gently pressed against various porous and non-porous surfaces to acquire LFPs. Thereafter, the obtained LFPs are stained by optimized $\mathrm{CeO}_{2}(15 \mathrm{ml}) \mathrm{NP}$ using soft feature brush with smooth powder brushing method. Finally, developed FPs are visualized under normal light using a Nikon D3100/AF-S Nikkor $50 \mathrm{~mm} \mathrm{f/2.8G} \mathrm{ED} \mathrm{lens} \mathrm{digital}$ camera. 
Table 1 Estimated average crystallite size, strain, and energy gap $\left(E_{\mathrm{g}}\right)$ values of the as-formed and calcined $\mathrm{CeO}_{2} \mathrm{NP}$

\begin{tabular}{|c|c|c|c|c|c|}
\hline \multirow[t]{2}{*}{ Sample } & \multirow[t]{2}{*}{ Fuel conc. (ml) } & \multicolumn{2}{|l|}{ Crystallite size $(\mathrm{nm})$} & \multirow[t]{2}{*}{ Strain $\times 10^{-3}$} & \multirow[t]{2}{*}{ Energy gap $\left(E_{\mathrm{g}}\right) \mathrm{eV}$} \\
\hline & & Scherrer's method & $\mathrm{W}-\mathrm{H}$ plots & & \\
\hline \multirow[t]{5}{*}{ As-formed } & 5 & 7 & 15 & 11 & 3.24 \\
\hline & 10 & 5 & 7 & 10 & 3.60 \\
\hline & 15 & 5 & 6 & 3 & 3.45 \\
\hline & 20 & 6 & 8 & 3 & 3.38 \\
\hline & 30 & 5 & 6 & 3 & 3.69 \\
\hline \multirow[t]{5}{*}{$800^{\circ} \mathrm{C}$} & 5 & 41 & 18 & 71 & 2.86 \\
\hline & 10 & 39 & 18 & 29 & 3.16 \\
\hline & 15 & 71 & 44 & 26 & 3.19 \\
\hline & 20 & 81 & 45 & 36 & 3.20 \\
\hline & 30 & 45 & 31 & 22 & 2.86 \\
\hline
\end{tabular}

(a)

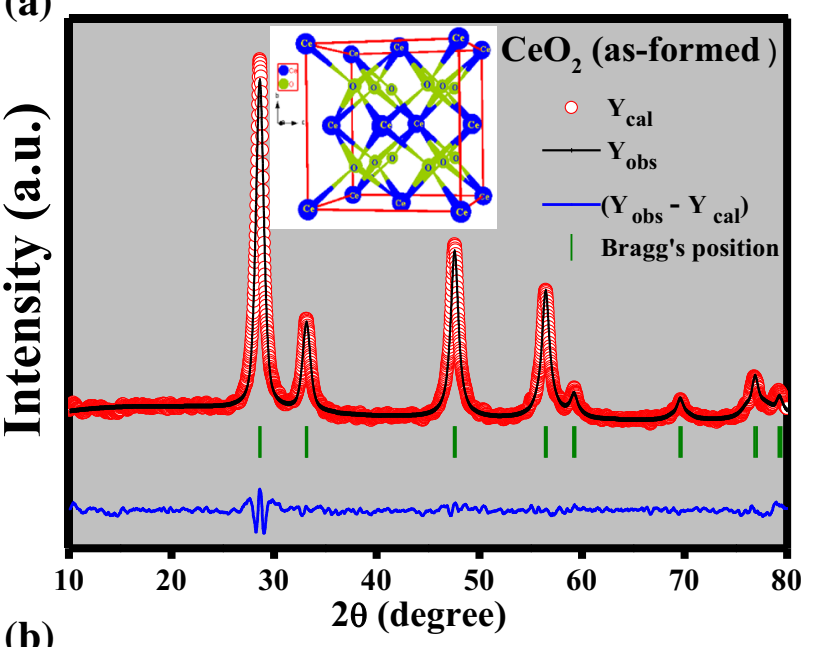

(b)

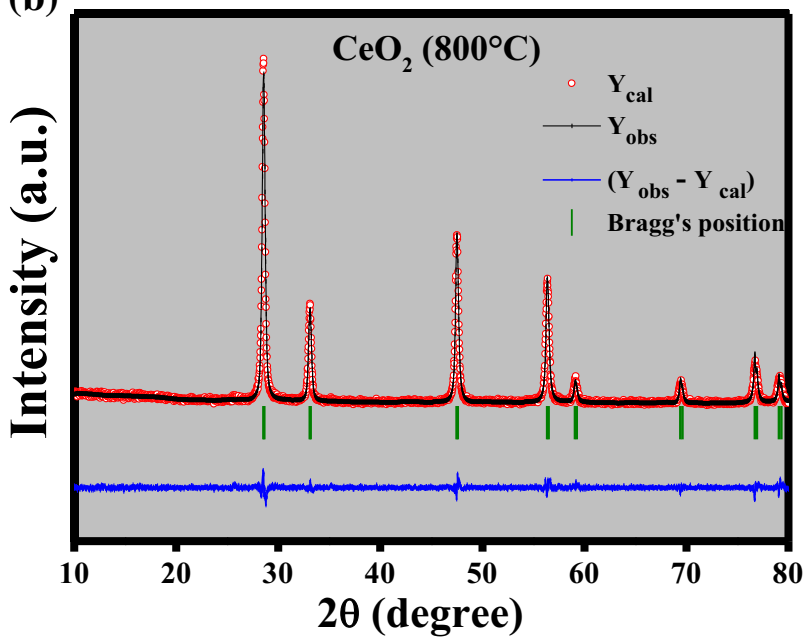

Fig. 8 Rietveld refinement of $\mathbf{a}$ as-formed and $\mathbf{b}$ calcined $\mathrm{CeO}_{2} \mathrm{NPs}$ $\left(800{ }^{\circ} \mathrm{C}\right)$ (Inset: Packing diagram)

\section{Results and discussion}

In order to inspect its suitability for recognizing latent fingerprints (LFPs), optimized $\mathrm{CeO}_{2} \mathrm{NPs}$ were stained on the LFPs developed on various non-porous substrates, namely stainless steel, glass, mobile screen and aluminium foil. In the present studies, all FPs were extracted from the same donor. Figure 2 display the LFPs images visualized by staining $\mathrm{CeO}_{2}$ NPs illuminated under normal white light. A complete ridge details including type 1,2 and 3 patterns with good adhesion, well-defined ridge flow and ridge orientation field is observed. Further, the FPs were well defined in terms of finger ridge details which due to their nano-sized $\mathrm{CeO}_{2}$. FP types have been described into three groups; (i) level 1 features are described by fingerprint ridge flow and general morphological information, (ii) level 2 features provide pattern matching followed detection of individual fingerprint ridges, (iii) level 3 features is defined as all attributes of a ridge, including shape, width, pores and curvature. Further, the stability of the prepared powders are assessed by aging the FPs up to 21 days and displayed comparable brightness (Fig. 3). The brightness of the $\mathrm{CeO}_{2}$ NPs-stained LFPs specifies that the NPs are physically and chemically steady in ambient conditions. Figure 4 displays detailed ridge patterns (type 1,2 and 3) developed on glass which consists of clear and distinct ridges of FPs can be undoubtedly detected under normal visible light. The level 2 details, such as the ridge bifurcation, island, scar, eye, bridge, ridge end, termination, lake and sweat pores, were clearly distinguished. Further, overlapped LFPs can be recognized on aluminium foil surfaces and shown in Fig. 5. The images clearly evident that the recognition of various ridge features includes level 


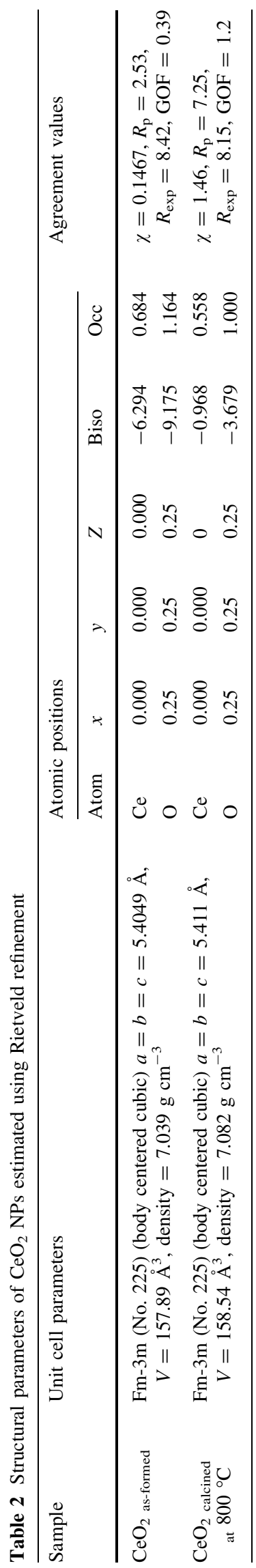

1, level 2 and also level 3 identification. Further, LFPs developed on glass were compared with commercially available $\left(\mathrm{Fe}_{2} \mathrm{O}_{3}\right.$ and $\left.\mathrm{TiO}_{2}\right)$ powders and shown in Fig. 6 . According to the detailed results obtained in the present study, we can observe the FP types specifically ridge flow, sweat pore, terminates, bifurcation and lack corresponding to the levels 1-3. Therefore, it is authorized that the probability for the recognition of the foremost ridge details of FPs in different surfaces was well established by optimized $\mathrm{CeO}_{2}$ NPs. The high-quality FP images developed on non-porous surfaces display the possible usage of $\mathrm{CeO}_{2}$ NPs fabricated via green synthesis route for forensic application.

Figure $7 \mathrm{a}, \mathrm{b}$ shows the PXRD patterns of as-formed and calcined $\left(800{ }^{\circ} \mathrm{C}\right) \mathrm{CeO}_{2}$ NPs. All the diffraction patterns are well indexed to JCPDS card No. 81-0792 (Malleshappa
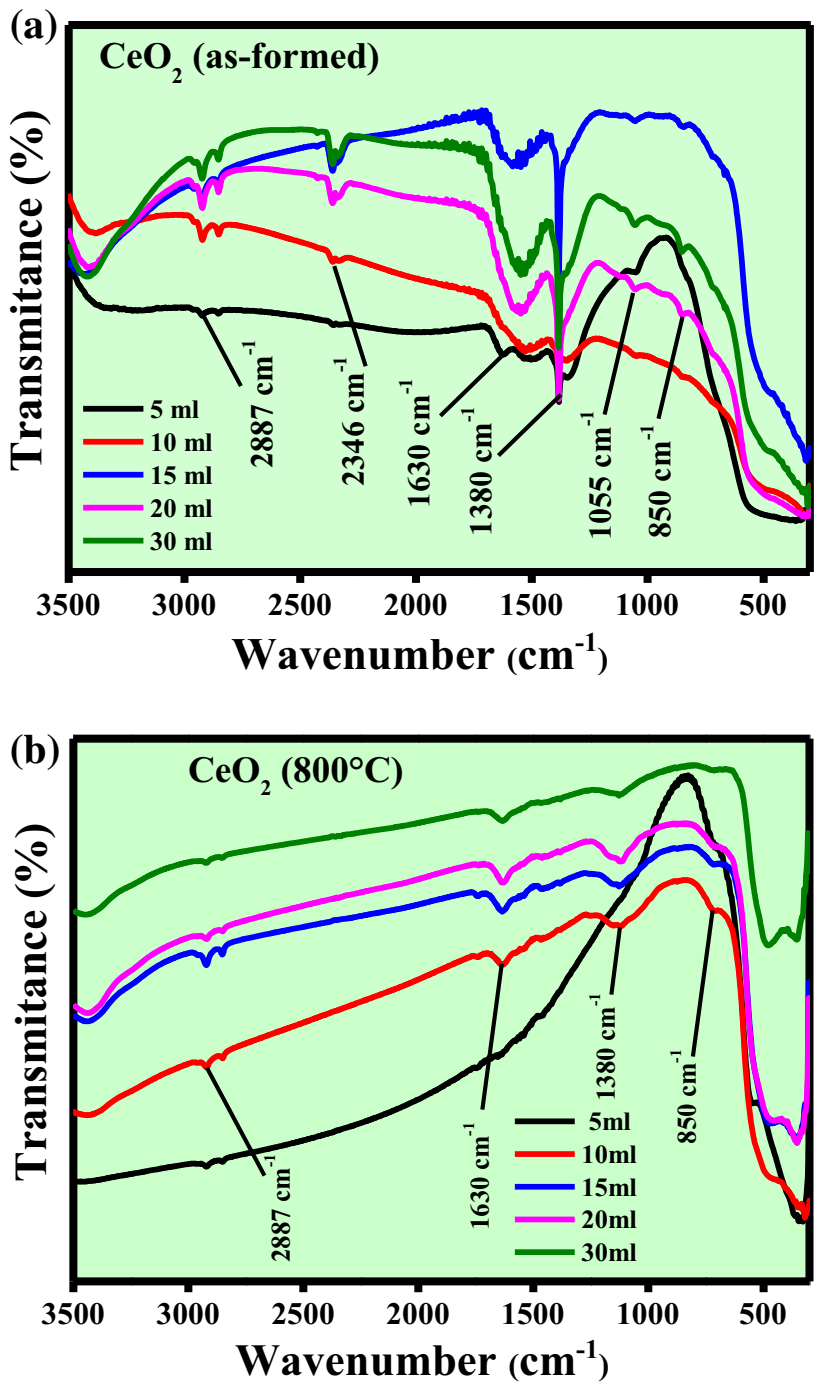

Fig. 9 FTIR spectra of $\mathbf{a}$ as-formed and $\mathbf{b}$ calcined $\mathrm{CeO}_{2}(5-30 \mathrm{ml})$ NPs 
(a)

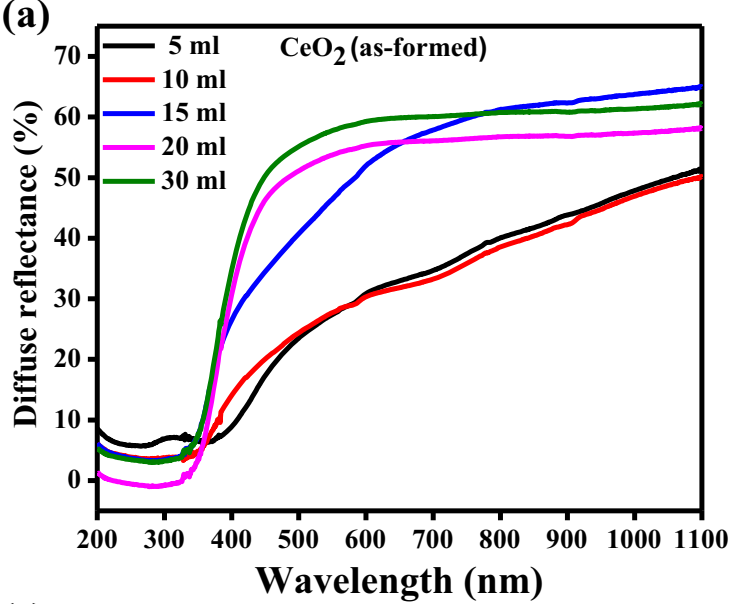

(c)

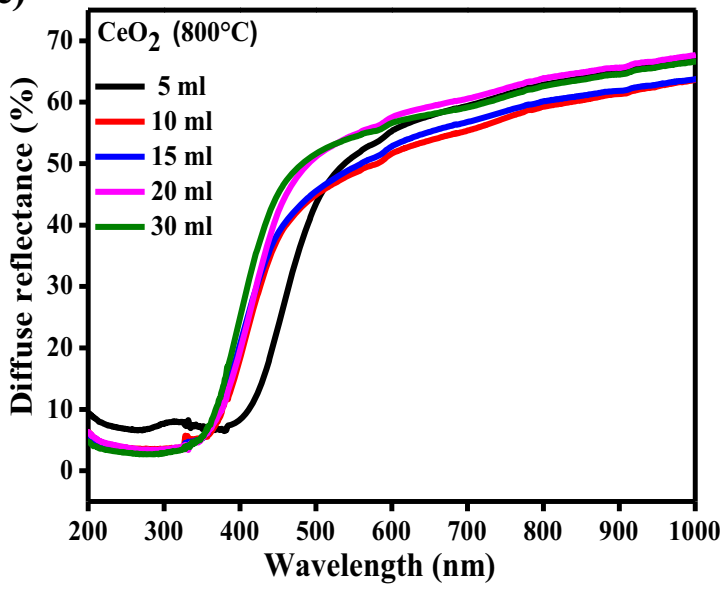

(b)

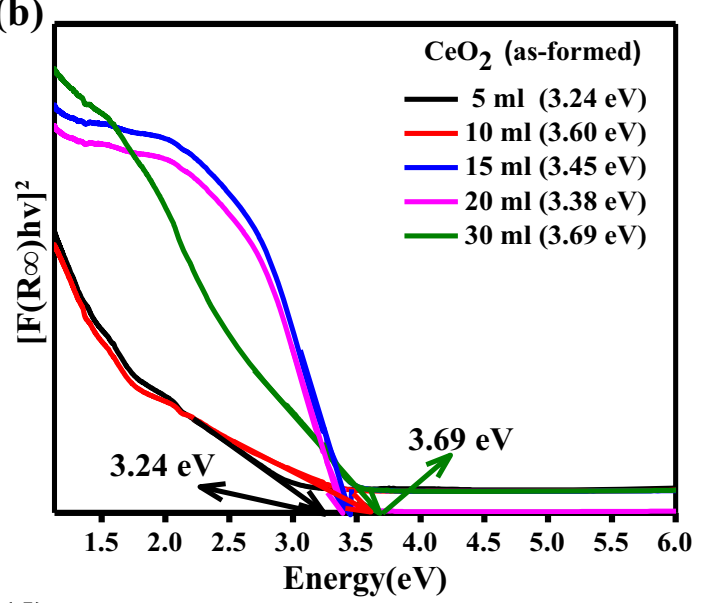

(d)

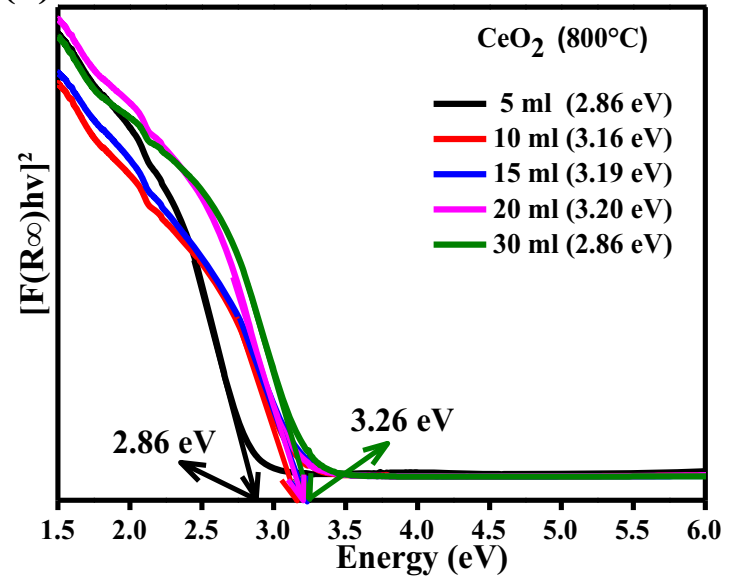

Fig. 10 a, c Diffuse reflectance spectra and $\mathbf{b}$, $\mathbf{d}$ energy band gap plots of as-formed and calcined $\mathrm{CeO}_{2} \mathrm{NPs}$

et al. 2014). The observed XRD peaks are well matched with the cubic planes (111), (200), (220), (311), (222), (400) and (311). No secondary or impurity peaks were present in the samples, which confirms the single cubic phase of $\mathrm{CeO}_{2}$. However a small lower angle $\left(28.51^{\circ}\right)$ peak shift in the plane (111) is observed due to compressive stress. The average crystallite size $(D)$ is estimated using Scherrer's relation:

$D=\frac{k \lambda}{\beta \cos \theta}$,

where $\lambda$ is the wavelength of the X-ray radiation $(1.54 \AA$ ), $K$ is the constant (0.9), $\beta$ is the full-width at half-maximum (FWHM), and $\theta$ is the diffracting angle. The estimated values of $D$ are tabulated in Table 1 . The lattice strain present in the product is estimated using the Williamson and Hall $(\mathrm{W}-\mathrm{H})$ plots using the following relation:

$\beta \cos \theta=\frac{k \lambda}{D}+4 \varepsilon \sin \theta$, where $\lambda$ is the wavelength of X-rays (1.54 $\AA$ ), $\beta$ is the full width at half maximum (in radians), $\theta$ is the diffraction angle, $k$ is the shape factor (0.9), $D$ is the crystallite size, and $\varepsilon$ is the micro-strain. The plots of $\beta \cos \theta \mathrm{v} / \mathrm{s} 4 \sin \theta$ are shown in Fig. 7c, d. The slope of line gives the strain $(\varepsilon)$ and intercept $(k \lambda / D)$ on $Y$ axis gives crystallite size. The estimated values of $D$ and lattice strain present in the samples are listed in Table 1.

One of the drawbacks of the diffraction patterns is accurate determination of crystal structure because of the overlapping of the diffraction peaks. Therefore, Rietveld refinement analysis is used to create the virtual separation of the overlapped peaks (Fig. 8). The Rietveld refinement method is used to calculate the entire powder pattern of the sample with the different refinable parameters and to minimize the difference between the observed and calculated pattern by least square method. The lattice parameters are evaluated by performing Rietveld refinement using FULLPROF suit program (Konysheva et al. 2010; 
(a)

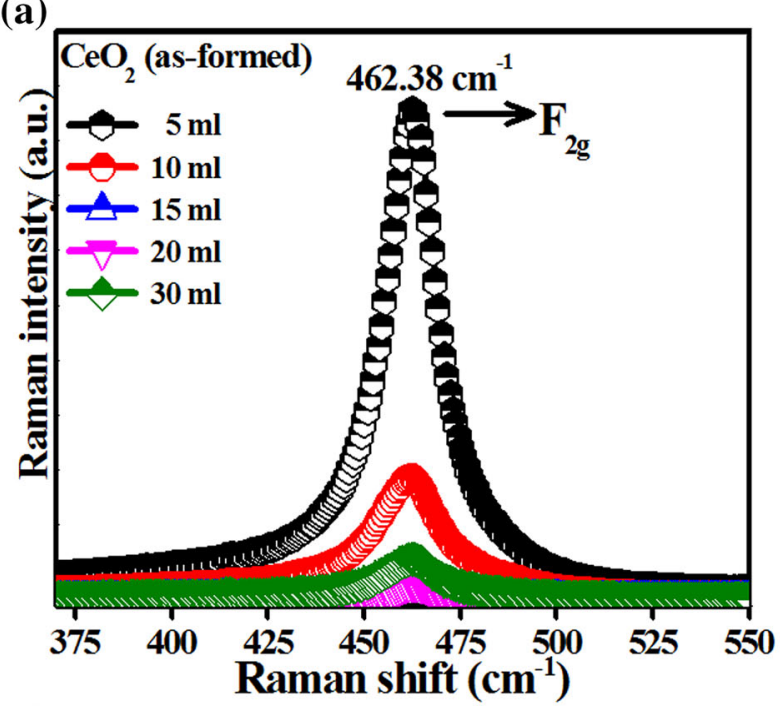

(c)

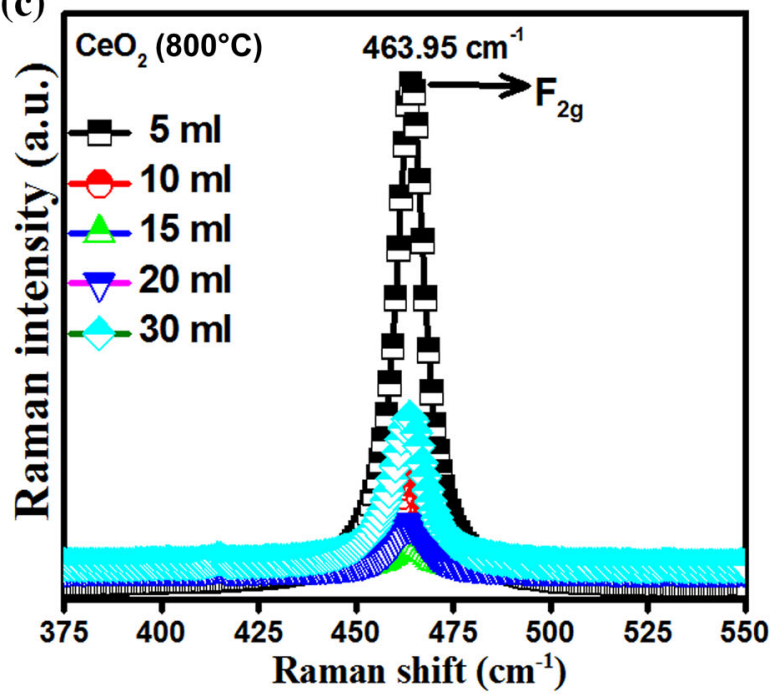

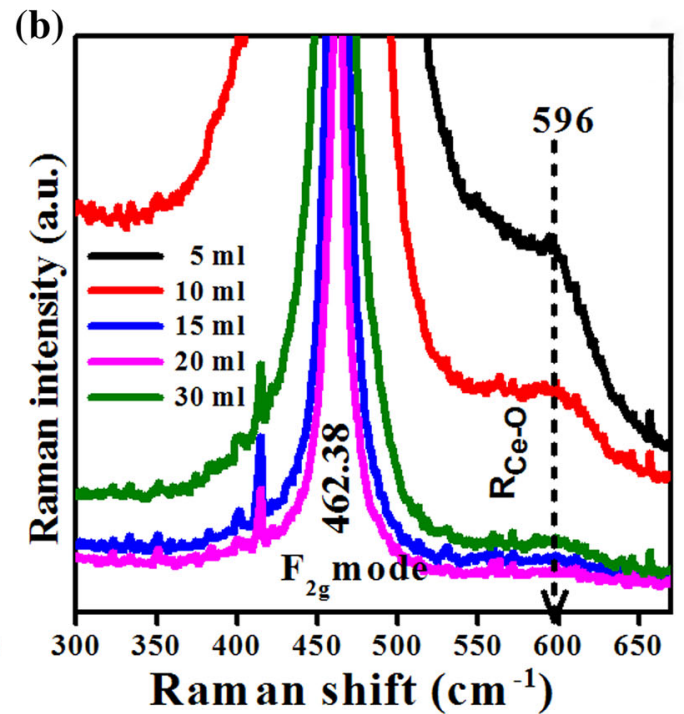

(d)

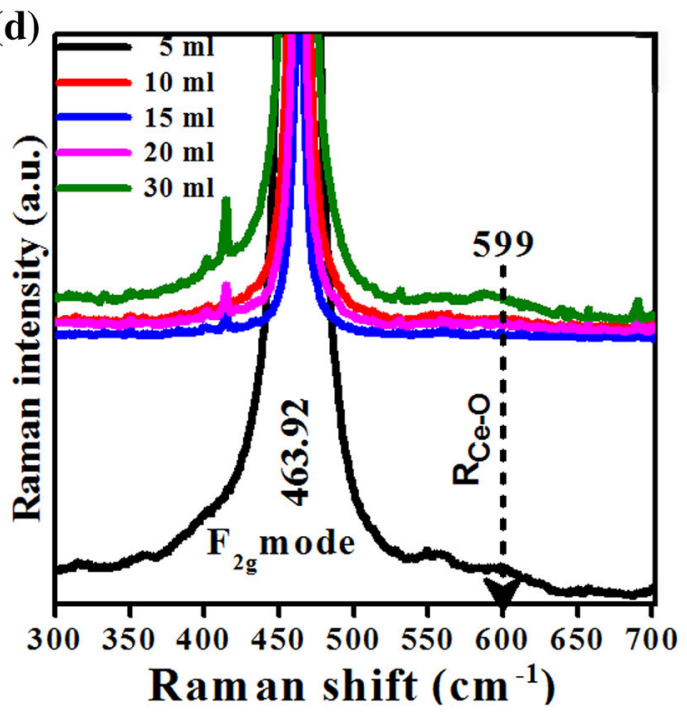

Fig. 11 a, $\mathbf{c}$ Raman spectra and $\mathbf{b}, \mathbf{d}$ enlarged portion of Raman spectra of as-formed and calcined $\mathrm{CeO}_{2} \mathrm{NPs}$

Table 3 Estimated Oxygen vacancies and crystallite size of $\mathrm{CeO}_{2} \mathrm{NPs}$

\begin{tabular}{lccccc}
\hline $\mathrm{CeO}_{2}$ & Conc. $(\mathrm{ml})$ & 463 Peak area & 600 Peak area & Area $_{\text {Oxygen vacancies }} /$ area & Crystallite size $($ Raman shift $)$ \\
\hline As-formed & 5 & 3460740 & 5928.18 & 0.171 & 10.27 \\
& 10 & 966704.5 & 1874.74 & 0.194 & 7.78 \\
& 15 & 179867.2 & 2274.19 & 1.260 & 15.53 \\
& 20 & 110568.5 & 660.32 & 0.597 & 12.86 \\
Calcined at $800{ }^{\circ} \mathrm{C}$ & 30 & 303690.6 & 428.47 & 0.141 & 9.22 \\
& 5 & 1269350.0 & 9281.99 & 0.731 & 23.78 \\
& 10 & 278712.5 & 3776.97 & 1.360 & 22.62 \\
& 15 & 110219.9 & 917.794 & 0.833 & 20.95 \\
& 20 & 162636 & 2975.44 & 1.830 & 20.13 \\
\end{tabular}




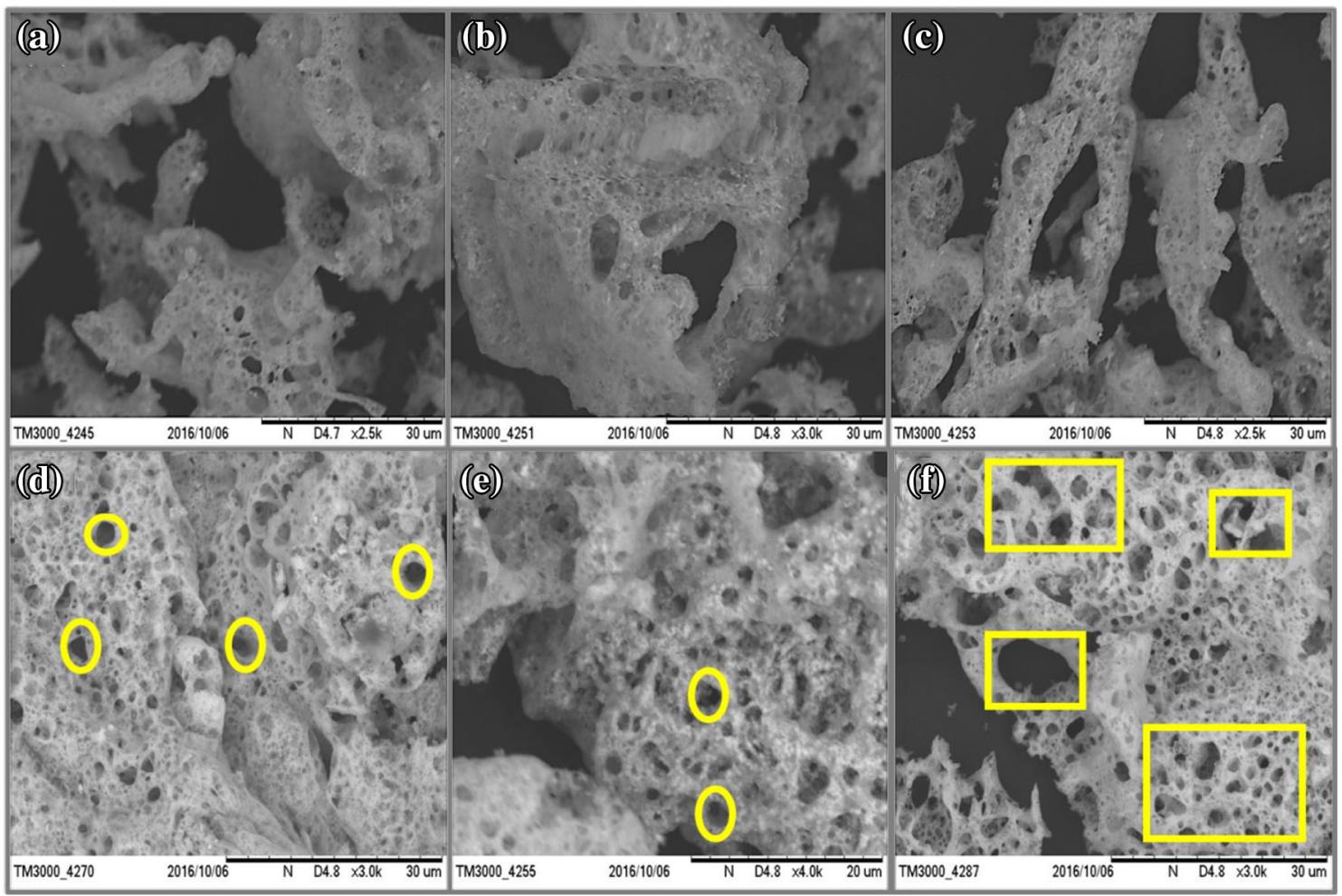

Fig. 12 SEM micrographs of a-c as-formed and $\mathbf{d}-\mathbf{f}$ calcined $\left(800{ }^{\circ} \mathrm{C}\right) \mathrm{CeO}_{2}(5,15$ and $30 \mathrm{ml}) \mathrm{NPs}$

Malleshappa et al. 2016; Shivaram et al. 2014; Xiaoyuan et al. 2001).

Pseudo-Voigt function has been used to fit the several parameters like one scale factor, one zero shifting, six background, three cell parameters, five shape and width of the peaks, one global thermal factor and two asymmetric factors. The refined parameters namely occupancy, atomic functional positions for $\mathrm{CeO}_{2}$ NPs are studied. The obtained results are in good agreement with the theoritically calculated ones. The space group used for the particular pattern is Fm-3m (No. 225). The refined parameters are tabulated in the Table 2 . The obtained $R_{\mathrm{p}}, R_{\mathrm{wp}}, R_{\mathrm{Braggs}}$, and $\chi^{2}$ values indicate the good fit of the profile.

Figures 9a, b shows the FTIR spectra of the as-formed and calcined $\mathrm{CeO}_{2}$ NPs prepared at different concentrations of $T$. indica extract $(5-30 \mathrm{ml})$. From the figure, it is observed that the principal vibrational modes of $\mathrm{CeO}_{2} \mathrm{NPs}$ were in good agreement with the reported literature. In the calcined sample, a diffuse band observed at $2918 \mathrm{~cm}^{-1}$ is due to the stretching vibration of the physically associated water $(\mathrm{O}-\mathrm{H})$ molecule. Another bending vibrational band of physically adsorbed water molecules is observed around $1619 \mathrm{~cm}^{-1}$. A weak broad peak observed at $314 \mathrm{~cm}^{-1}$ which is assigned to the $\mathrm{Ce}-\mathrm{O}$ stretching band (Binet et al. 1994; Khan et al. 2013; Sahu and Rao 2000). The peak at
$1350 \mathrm{~cm}^{-1}$ is a characteristic vibration mode of $\mathrm{CeO}_{2}$ (Ketzial and Nesaraj 2011; Yan and Zhu 2008).

The diffuse reflectance (DR) spectra of the as-formed and calcined samples of $\mathrm{CeO}_{2}$ NPs are shown in Fig. 10a, c. The spectra are recorded in the range of 200-1100 nm wavelength at room temperature. It can be seen from the Fig. 10a, c that a strong absorption peak is observed in the range of $350-400 \mathrm{~nm}$.

To determine the energy band gap, Kubelka-Munk function is used (Yuan et al. 2016). The Kubelka-Munk function $\mathrm{F}\left(R_{\infty}\right)$ and band gap energy $(h v)$ is estimated by utilizing the following equations:

$\mathrm{F}\left(R_{\infty}\right)=\frac{\left(1-R_{\infty}\right)^{2}}{2 R_{\infty}}$,

$h v=\frac{1240}{\lambda}$

where $R_{\infty}$ is the reflection coefficient of the sample and $\lambda$ is the absorption wavelength. The energy band gap values were evaluated and are summarized in Table 1. The energy band gap $\left(E_{\mathrm{g}}\right)$ values of as-formed $\mathrm{CeO}_{2} \mathrm{NPs}$ are found to be in the range of $\sim 3.24-3.69 \mathrm{eV}$ and that for calcined sample it was found to be $\sim 2.86-3.20 \mathrm{eV}$, which is much lesser than the as-formed $\mathrm{CeO}_{2}$ due to oxygen vacancies present in the sample (Fig. 10b, d), therefore, which gives 
Fig. 13 a TEM, b enlarged view, c HRTEM image and d SAED pattern of as-formed $\mathrm{CeO}_{2}(15 \mathrm{ml}) \mathrm{NPs}$

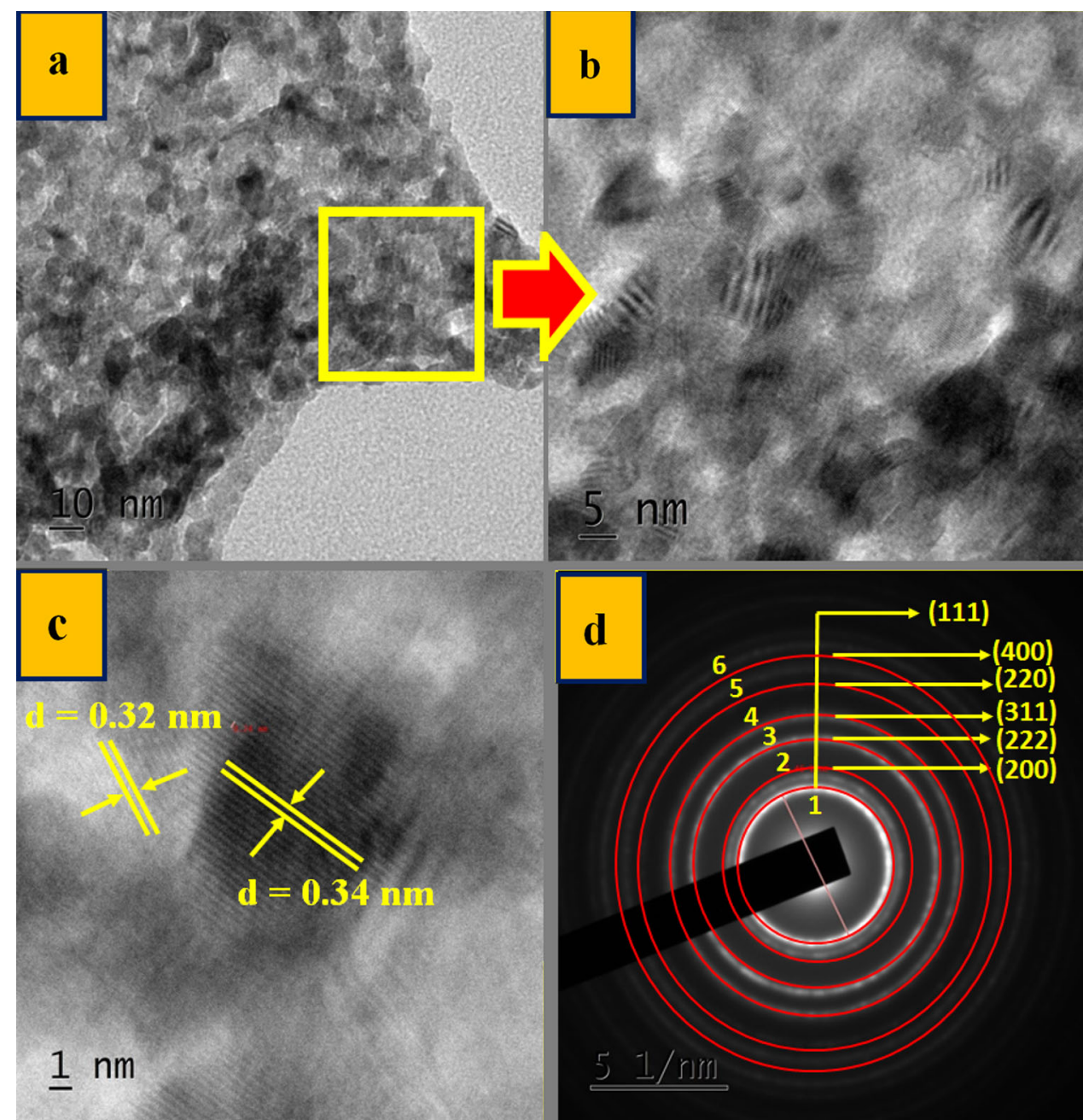

the evidence for the quantum confinement of calcined $\mathrm{CeO}_{2}$ NPs. The decrease in $\mathrm{E}_{\mathrm{g}}$ also indicate the red shift in the calcined sample (Table 1) (Li et al. 2015; Jorge et al. 2012; Periyat et al. 2011).

Figure 11a, c shows the Raman spectra of as-formed and calcined $\mathrm{CeO}_{2}$ NPs and its enlarged portions are shown in Fig. 11b, d. The spectra exhibit four characteristic modes at $\sim 254,460,546$ and $612 \mathrm{~cm}^{-1}$ (Balakrishnan et al. 2013). The mode at 254 and $460 \mathrm{~cm}^{-1}$ are attributed to twice degenerated 2TA and first order $\mathrm{F}_{2 \mathrm{~g}}$, respectively. An $\mathrm{F}_{2 \mathrm{~g}}$ mode confirms the fluorite cubic structure of the prepared samples and also signifies the symmetrical stretching vibration of the $\mathrm{CeO}_{8}$ vibrational unit. A broad and asymmetric mode at $\sim 460 \mathrm{~cm}^{-1}$ is red shifted as compared to bulk form owing to oxygen defects, phonon confinement, size distribution, deviation in phonon relaxation and strain present in the sample $(\mathrm{Xu}$ et al. 2017; Lopez et al. 2015). The other modes at $\sim 546$ and $612 \mathrm{~cm}^{-1}$ are due to oxygen vacancies (intrinsic and extrinsic). The relative intensities of Raman modes at $\sim 460,546$ and $612 \mathrm{~cm}^{-1}$ are calculated based on the relation (Arumugam et al. 2015):

$\frac{\text { Oxygen vacancies }}{\mathrm{F}_{2 \mathrm{~g}}}=\frac{\left(\text { Area }_{R_{\mathrm{Ce}-\mathrm{O}}}\right)}{{\text { Area } \mathrm{F}_{2 \mathrm{~g}}}}$.

The rate of oxygen vacancies is estimated and given in Table 3. The probable reaction mechanism for intrinsic oxygen vacancies are:

$\mathrm{Ce}_{\mathrm{Ce}}+2 \mathrm{O}_{\mathrm{o}} \rightarrow \mathrm{V}^{\prime \prime \prime \prime}+2 \mathrm{~V}_{\mathrm{o}}^{*}+\mathrm{CeO}_{2}$,

$\mathrm{Ce}_{\mathrm{Ce}} \rightarrow \mathrm{V}_{\mathrm{Ce}}^{\prime \prime \prime \prime}+\mathrm{Ce}_{\mathrm{i}}^{\cdots \cdots}$,

$\mathrm{O}_{\mathrm{o}} \rightarrow \mathrm{V}_{\mathrm{o}}^{*}+\mathrm{O}_{\mathrm{i}}^{\prime}$.

Besides, the average crystallite size of the $\mathrm{CeO}_{2}$ powder scale down to nano range leads to more oxygen loss (Jiang et al. 2012).

Figure 12 shows the SEM micrographs of as-formed and calcined $\mathrm{CeO}_{2}$ NPs. It can be observed from the Fig. 12a-c 
Fig. 14 a, b TEM, c HRTEM image and $\mathbf{d}$ SAED pattern of calcined $\mathrm{CeO}_{2}(15 \mathrm{ml}) \mathrm{NPs}$
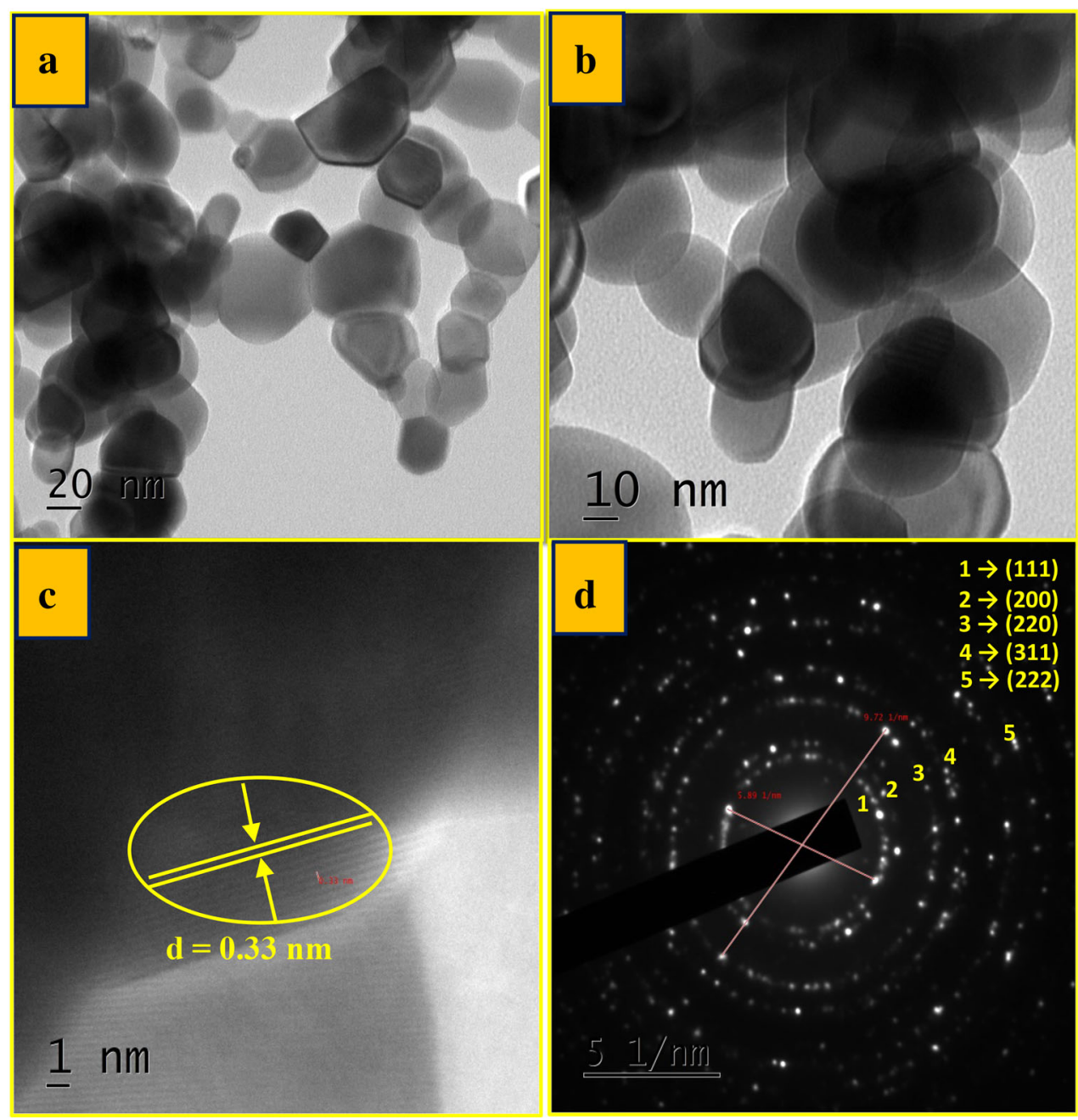

that the particles are porous in nature. Particles are mostly containing voids with different sizes due to the evolution of large amount of gases during the combustion. The porosity and size of the voids increase with increase in temperature as observed in Fig. 12d-f. TEM, HRTEM images and SAED patterns of as-formed $\mathrm{CeO}_{2}$ NPs are shown Fig. 13. The particles with agglomeration are observed in Fig. 13a. The estimated crystallite size varies between $\sim 5$ and $20 \mathrm{~nm}$ which is in good agreement with the PXRD results. The interplanar distance (d) was found to be around $\sim 0.32-0.34 \mathrm{~nm}$ (Fig. 13c). The polycrystalline nature of the sample was further confirmed by SAED patterns. Figure 14 shows the TEM, HRTEM images and SAED patterns of calcined $\mathrm{CeO}_{2}$ NPs. It is evident that in calcined samples the crystallinity has been increased as shown in Fig. 14a, b. The interplanar spacing $d$ value is found to be $\sim 0.33 \mathrm{~nm}$.

Photoluminescence excitation spectrum of as-formed $\mathrm{CeO}_{2}$ NPs upon $530 \mathrm{~nm}$ emission wavelength as shown in inset of Fig. 15a. The spectrum exhibit a sharp peak at $\sim$
$386 \mathrm{~nm}$. Figure 15a shows the PL emission spectra of asformed $\mathrm{CeO}_{2}$ NPs prepared with various fuel concentration under $\lambda_{\text {Exc }}=386 \mathrm{~nm}$. The spectra exhibits peaks at $\sim 362$, 391 and $441 \mathrm{~nm}$ may be attributed to surface defects, charge transition from the $4 \mathrm{f}$ band to the valence band of $\mathrm{CeO}_{2}$ and oxygen vacancies ( $\mathrm{Li}$ et al. 2008; Dang et al. 2010; Luo et al. 2015). The emission spectra of calcined $\mathrm{CeO}_{2}$ NPs excited under $386 \mathrm{~nm}$ wavelength as shown in Fig. 15b, e. The spectra exhibits characteristic peaks at 485, 528 and $542 \mathrm{~nm}$ are believed to be due to surface defects and oxygen vacancies (Li et al. 2011; Arunkumar et al. 2014; Morshed et al. 1997; Maensiri et al. 2007).

The Commission Internationale de L'Eclairage (CIE) diagram of as-formed and calcined $\mathrm{CeO}_{2}$ NPs is shown in Fig. 16a. In general, the emission color of any phosphor can be represented by the $(x, y)$ chromaticity co-ordinates (Sayed et al. 2011). The CIE co-ordinates are estimated using PL emission spectra and the values are listed in a Table 4. It is noticed that the CIE co-ordinates of asformed and calcined samples were located in the blue 

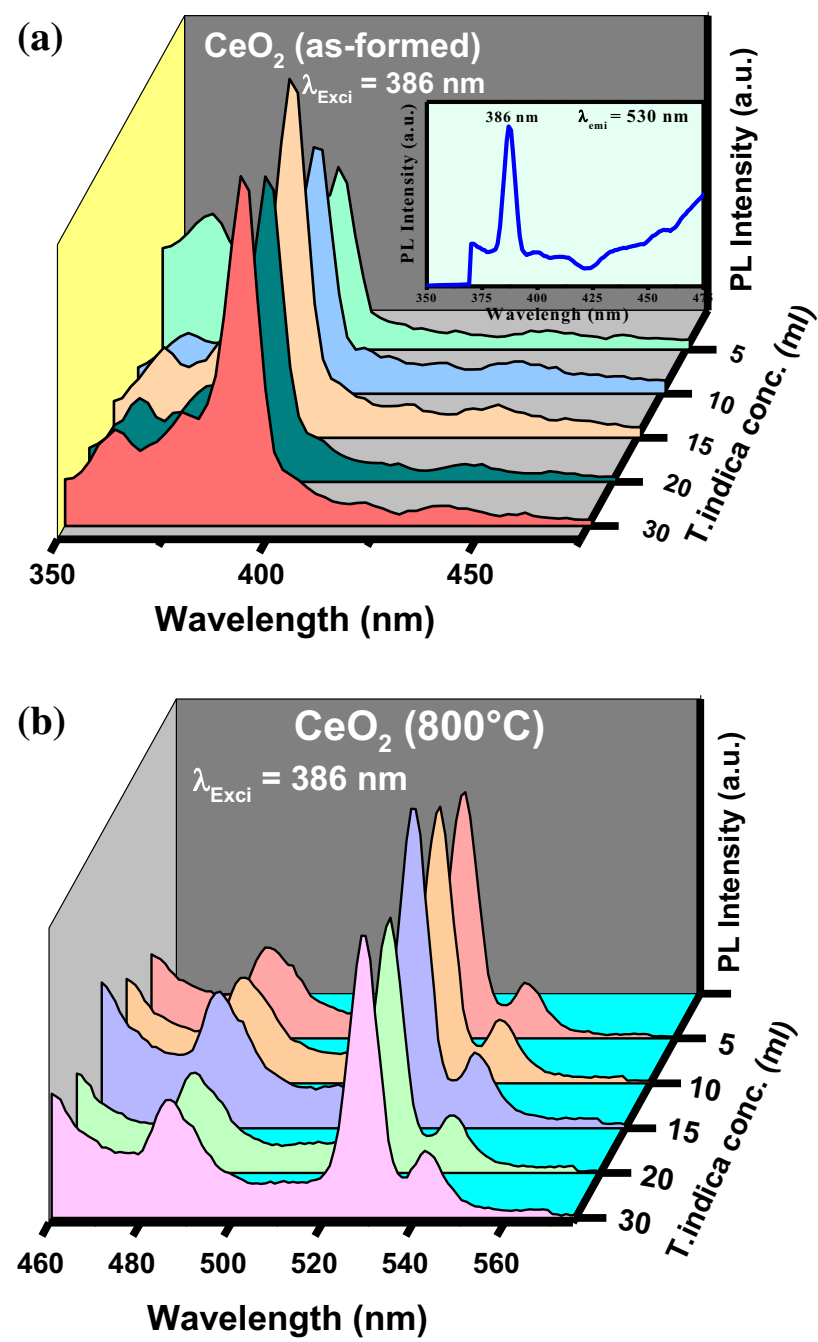

Fig. 15 PL emission spectra of $\mathbf{a}$ as-formed and $\mathbf{b}$ calcined $\mathrm{CeO}_{2} \mathrm{NPs}$ excited at $386 \mathrm{~nm}$ wavelength (Inset: excitation spectrum recorded at $530 \mathrm{~nm}$ emission)

region. The correlated color temperature (CCT) is one of the important parameters to know the color appearance of the light emitted by a source, relating it is color with respect to a reference light source when it is heated up to a specific temperature, in Kelvin (K) (Guo et al. 2012). The CCT is calculated and shown in Fig. 16b by the method as reported earlier (Shrivastava et al. 2015). The obtained values are summarized in Table 4.

Photocatalytic studies are carried out using $150 \times 75 \mathrm{~mm}$ batch reactor at room temperature. Methylene blue is used as dye for photo degradation of $\mathrm{CeO}_{2} \mathrm{NPs}$ as catalyst. The particle size of as-formed $\mathrm{CeO}_{2} \mathrm{NPs}$ prepared with $T$. indica fuel $(15 \mathrm{ml})$ was very small $(5.2 \mathrm{~nm})$ compared to other concentrations of the fuel; due to this reason, $\mathrm{CeO}_{2} \mathrm{NPs}$ with $15 \mathrm{ml}$ samples were considered for photocatalytic activity. When solution of $\mathrm{CeO}_{2} \mathrm{NPs}$ with (a)

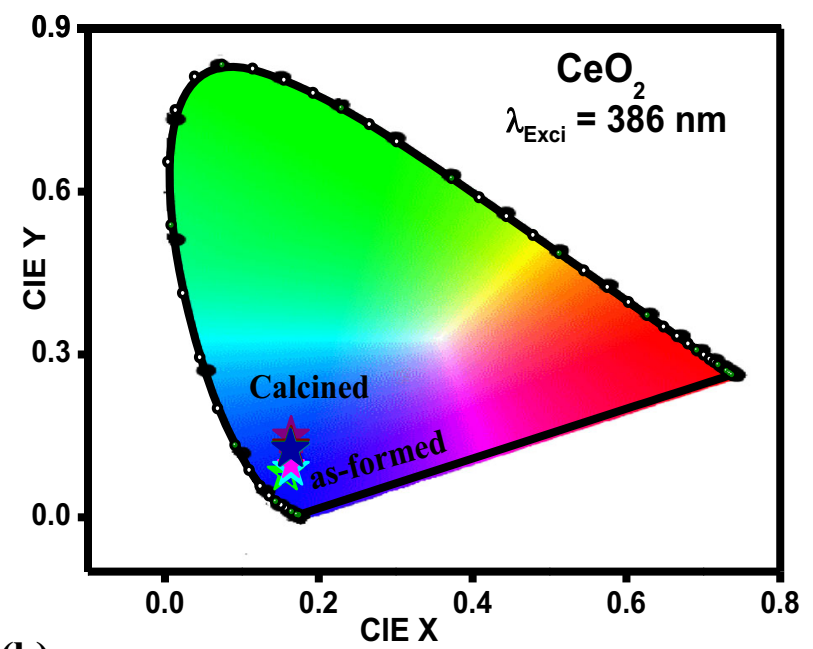

(b)

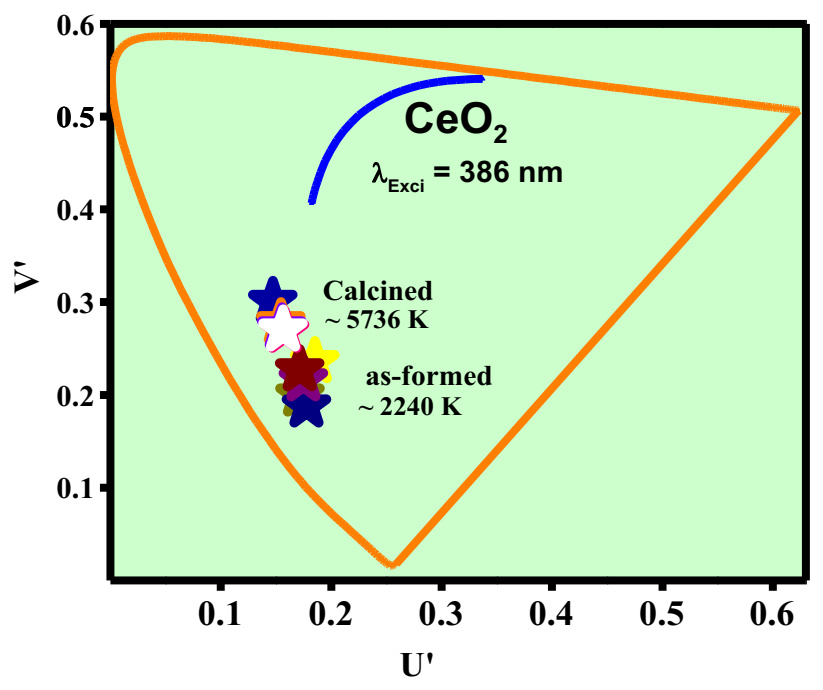

Fig. 16 a CIE and b CCT diagrams of as-formed and calcined $\mathrm{CeO}_{2}$ (5-30 ml) NPs

dye was exposed to UV light, electron transfer from valence to conduction band by absorbing UV light. The $\mathrm{e}^{-}-$ $\mathrm{h}^{+}$pairs offers efficient path for oxidation and reduction reactions to degradation of MB dye. The generated electrons react with molecular oxygen and produce hydrogenperoxide molecules in the aqueous medium and expressed by the following reactions. Conversely, the generated holes produce hydroxyl radicals from the water. These hydroxyl radicals act as an influential oxidizing agent to degradation of pollutant MB. The effect of $\mathrm{pH}$ concentration on the photocatalytic activity is also studied in detail. It is clear from the literature that photocatalytic activity depends on the $\mathrm{pH}$ value of solution. Here, four different $\mathrm{pH}$ concentrations effect on photocatalytic activity was studied. Surface property of $\mathrm{CeO}_{2}$ and dislocation of dye molecule varies with the different $\mathrm{pH}$ value. In basic media, there is 
Table 4 Photometric values of as-formed and calcined $\mathrm{CeO}_{2} \mathrm{NPs}$

\begin{tabular}{|c|c|c|c|c|c|c|}
\hline \multirow[t]{2}{*}{ Sample } & \multirow[t]{2}{*}{ Fuel conc. (ml) } & \multicolumn{2}{|l|}{ CIE } & \multicolumn{2}{|l|}{ CCT } & \multirow[t]{2}{*}{$\mathrm{CCT}(\mathrm{K})$} \\
\hline & & $X$ & $Y$ & $U^{1}$ & $V^{1}$ & \\
\hline \multirow[t]{5}{*}{ As-formed } & 5 & 0.1786 & 0.1011 & 0.1853 & 0.2360 & 2362 \\
\hline & 10 & 0.1572 & 0.0812 & 0.1718 & 0.1998 & 2119 \\
\hline & 15 & 0.1589 & 0.0747 & 0.1777 & 0.1880 & 1963 \\
\hline & 20 & 0.1640 & 0.0901 & 0.1748 & 0.2161 & 2239 \\
\hline & 30 & 0.1633 & 0.0966 & 0.1716 & 0.2270 & 2500 \\
\hline \multirow[t]{5}{*}{$800{ }^{\circ} \mathrm{C}$} & 5 & 0.1642 & 0.1491 & 0.1472 & 0.3009 & 7784 \\
\hline & 10 & 0.1640 & 0.1640 & 0.1545 & 0.2780 & 5853 \\
\hline & 15 & 0.1630 & 0.1630 & 0.1554 & 0.2722 & 5248 \\
\hline & 20 & 0.1643 & 0.1643 & 0.1580 & 0.2687 & 4800 \\
\hline & 30 & 0.1634 & 0.1634 & 0.1565 & 0.2701 & 4996 \\
\hline
\end{tabular}

(a)

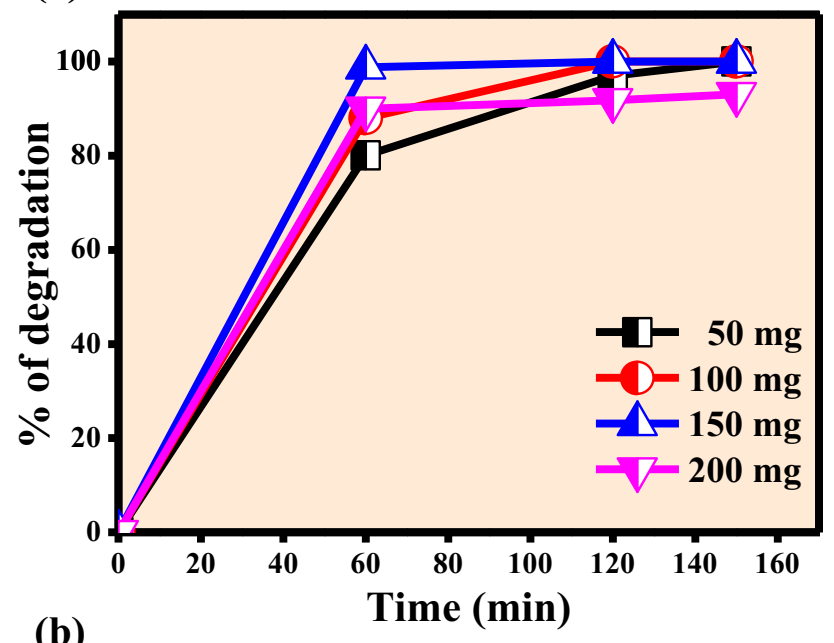

(b)

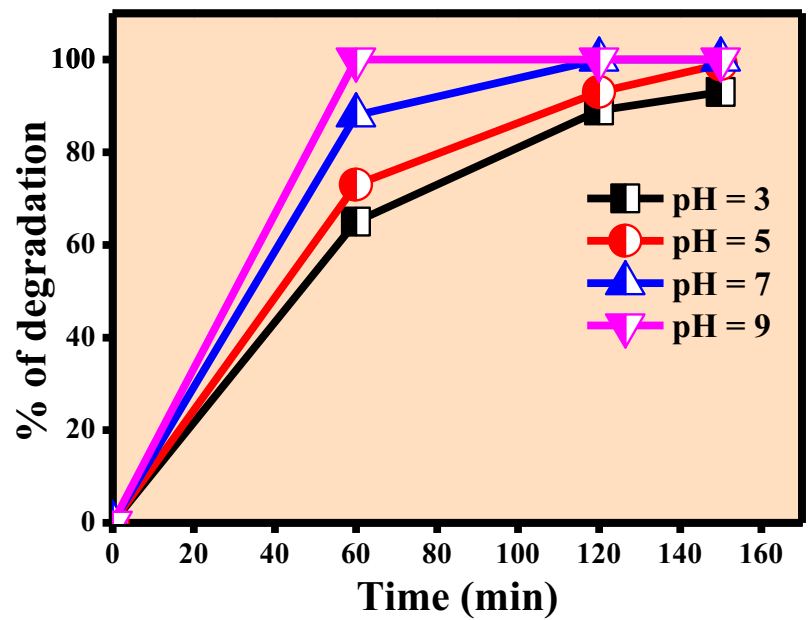

Fig. 17 Effect of a catalytic load and $\mathbf{b} \mathrm{pH}$ value on photocatalytic activity of calcined $\mathrm{CeO}_{2}(15 \mathrm{ml}) \mathrm{NPs}$ an increase in hydroxyl radicals which leads to the increase in photocatalytic activity (Arul et al. 2015; Khan et al. 2014; Lei et al. 2015).

Figure 17a shows the effect of catalytic load on the catalytic activity of $\mathrm{CeO}_{2}$ NPs. To study the effect of catalytic load $5 \mathrm{ppm}$ in $100 \mathrm{ml}$ of water is maintained constant with varying catalytic load. The catalytic load increased up to $150 \mathrm{mg}$; the percentage of degradation was also increased and then remains constant for $200 \mathrm{mg}$ catalytic load owing to the formation of turbidity in the solution which reduces the penetration of light through the solution. The following reactions explain the splitting of water molecule and dye degradation into organic acid and by-products.

$h_{\mathrm{vb}}^{+}+\mathrm{OH} \rightarrow \mathrm{OH}^{\cdot}$

$\mathrm{e}_{\mathrm{CB}}^{-}+\mathrm{O} \rightarrow \mathrm{O}_{2}^{--}$

$\left(\mathrm{OH}^{\cdot}, \mathrm{O}_{2}^{--}\right)+\mathrm{MB}$ dye $\rightarrow$ Degradation of dye,

$\mathrm{H}_{2} \mathrm{O}+\mathrm{e}^{-} \rightarrow \mathrm{H}+\mathrm{OH}+\mathrm{e}^{-}$,

$\mathrm{H}_{2} \mathrm{O}+h v \rightarrow \mathrm{H}+\mathrm{OH}$,

$\mathrm{OH}+\mathrm{OH} \rightarrow \mathrm{H}_{2} \mathrm{O}_{2}$,

$\mathrm{H}+\mathrm{H} \rightarrow \mathrm{H}_{2}$,

$\mathrm{H}_{2} \mathrm{O}_{2}+h v \rightarrow \mathrm{OH}+\mathrm{OH}$,

$\mathrm{OH}+\mathrm{MB}-\mathrm{OH}+\mathrm{OH} \rightarrow \mathrm{MB}-(\mathrm{OH})_{2}+\mathrm{OH}$

$\rightarrow \mathrm{MB}-(\mathrm{OH})_{3}$,

$\mathrm{MB}-(\mathrm{OH})_{3} \rightarrow$ amines, organics acids, etc

$$
\rightarrow \mathrm{Co}_{2}+\mathrm{H}_{2} \mathrm{O} \text {. }
$$

Figure $17 \mathrm{~b}$ shows the effect of $\mathrm{pH}$ on catalytic activity of $\mathrm{CeO}_{2}$ NPs. To study the effect of $\mathrm{pH}, 5 \mathrm{ppm}$ dye 
Fig. 18 Schematic representation to show the mechanism of photocatalytic degradation of $\mathrm{MB}$ using $\mathrm{CeO}_{2}$ NPs
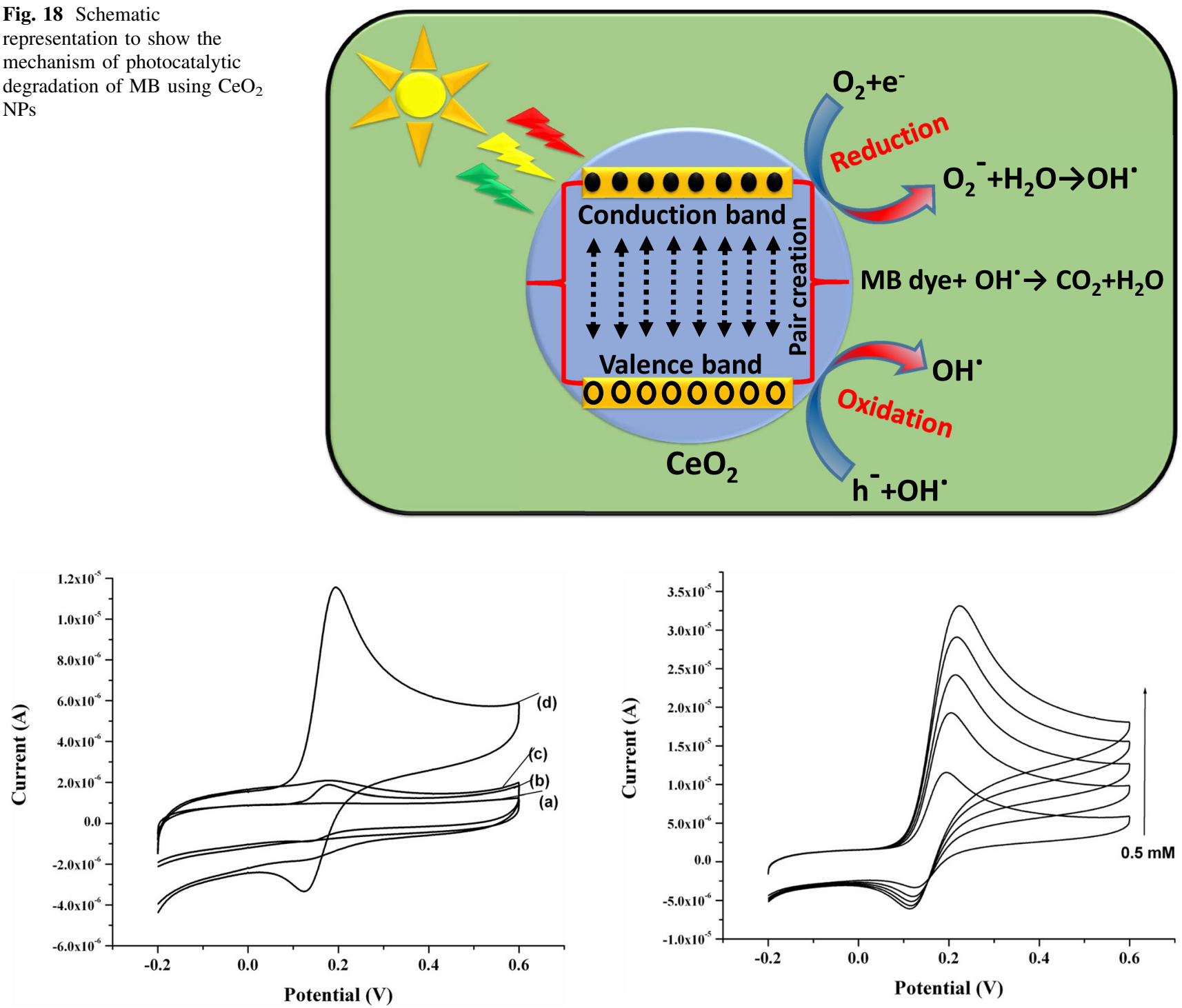

Fig. $19 \mathrm{CV}$ plots of a bare carbon paste electrode in PBS buffer of $\mathrm{pH}=7$, b $a+0.5 \mathrm{mM}$ dopamine, c calcined $\mathrm{CeO}_{2}$ NPs modified carbon paste electrode in PBS buffer of $\mathrm{pH} \mathrm{7,} \mathrm{d} c+0.5 \mathrm{mM}$ dopamine

concentration was maintained constant in $100 \mathrm{ml}$ of water with $100 \mathrm{mg}$ of catalytic load by varying $\mathrm{pH}$ concentrations. For $\mathrm{pH} 9, \mathrm{CeO}_{2} \mathrm{NPs}$ have shown good photocatalytic activity while for $\mathrm{pH} 3$ it exhibit poor activity which confirms that in basic medium activity it was more when compared with the acidic medium (Magesh et al. 2009; Wetchakun et al. 2012). Figure 18 shows the schematic representation of the mechanism involved in photocatalytic degradation of the $\mathrm{MB}$ dye using $\mathrm{CeO}_{2} \mathrm{NPs}$ as photocatalyst.

Figure 19 shows the cyclic voltagrams (CVs) of asformed $\mathrm{CeO}_{2}$ NPs modified carbon paste electrode recorded in $0.5 \mathrm{mM}$ dopamine concentration in PBS buffer of $\mathrm{pH}$ 7. The bare carbon paste electrode shows only a small

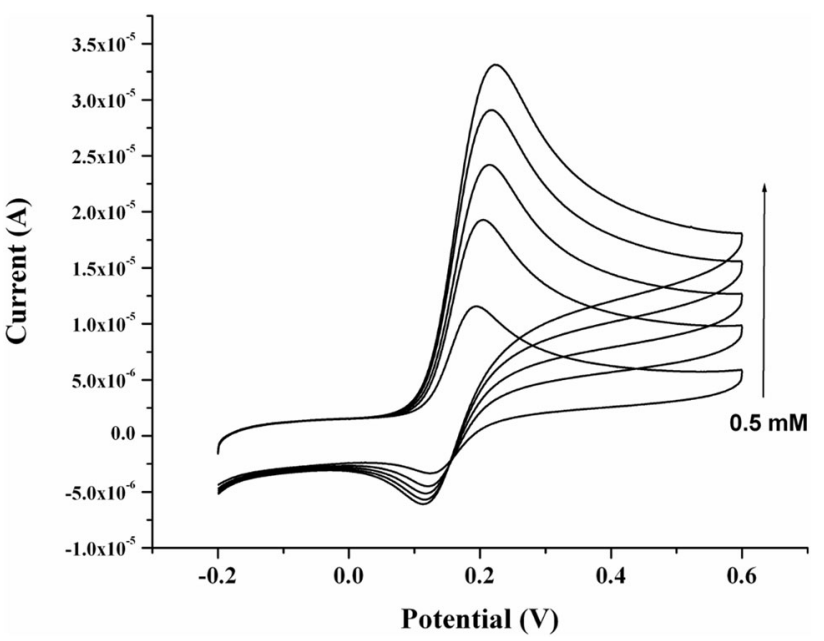
electrode in PBS buffer of $\mathrm{pH}=7$ with dopamine concentrations ranging from 0.5 to $0.25 \mathrm{mM}$

oxidation peak centered at $0.2 \mathrm{~V}$. Whereas, $\mathrm{CeO}_{2} \mathrm{NPs}$ modified carbon paste electrode shows well-defined oxidation peak at $0.2 \mathrm{~V}$ and also corresponding reduction peak around $0.13 \mathrm{~V}$ (Fig. 19c). These results confirm that presence of $\mathrm{CeO}_{2}$ NPs on electrode assists in catalytic oxidation of dopamine. With increase in dopamine concentration, the anodic peak current also increases as shown in Fig. 20. This confirms that the redox peak corresponds to surface confined species ( $\mathrm{Li}$ et al. 2015). The ratio of anodic and cathodic peak current was approximately equal to one, which indicates that the electrochemical reaction is highly reversible (Wei et al. 2006). The electrochemical sensing results obtained for modified electrodes $\mathrm{CeO}_{2}$ NPs reveals the highly stable and can be used to fabricate good electrochemical sensing devices.
Fig. $20 \mathrm{CV}$ plots of calcined $\mathrm{CeO}_{2} \mathrm{NPs}$ modified carbon paste 


\section{Conclusions}

A simple green combustion route is used to prepare $\mathrm{CeO}_{2}$ NPs using T. indica fruit extract as fuel. The structural, optical and catalytic properties of as-formed as well as calcined $\mathrm{CeO}_{2}$ NPs are studied in detail. A cubic phase of prepared $\mathrm{CeO}_{2} \mathrm{NPs}$ is confirmed by PXRD patterns. The crystallite size, energy band gap and PL properties are highly dependent on concentration of fuel. The prepared $\mathrm{CeO}_{2}$ NPs are highly pores and irregular shape with large number of surface voids. The particle size was estimated from TEM and found to be in the range of 5-40 $\mathrm{nm}$ which is in good agreement with PXRD results. From the CIE chromaticity diagrams, a blue color emission from the prepared sample is noticed. Further, modified electrodes by $\mathrm{CeO}_{2}$ NPs exhibit enhanced electrochemical sensing properties and, hence, can be used to fabricate the electrochemical sensing devices. The $\mathrm{CeO}_{2}$ NPs also showed good photocatalytic activity with respect to variation in $\mathrm{pH}$ and catalytic load. The above results clearly confirmed that the product obtained in green combustion route is quite useful for multifunctional applications.

Acknowledgements The author Dr. H Nagabhushana thanks VGST, Govt. of Karnataka, India [VGST/KFIST-4/GRD-489] for the sanction of this Project.

Open Access This article is distributed under the terms of the Creative Commons Attribution 4.0 International License (http:// creativecommons.org/licenses/by/4.0/), which permits unrestricted use, distribution, and reproduction in any medium, provided you give appropriate credit to the original author(s) and the source, provide a link to the Creative Commons license, and indicate if changes were made.

\section{References}

Arul NS, Mangalaraj D, Ramachandran R, Grace AN, Han JI (2015) Fabrication of $\mathrm{CeO}_{2} / \mathrm{Fe}_{2} \mathrm{O}_{3}$ composite nanospindles for enhanced visible light driven photocatalysts and supercapacitor electrodes. J Mater Chem A 3:15248-15258

Arumugam A, Karthikeyan C, Hameed ASH, Gopinath K, Gowri S, Karthika V (2015a) Synthesis of cerium oxide nanoparticles using Gloriosa superba L. leaf extract and their structural, optical and antibacterial properties. Mater Sci Eng A 49:408-415

Arumugam A, Karthikeyan C, Haja Hameed AS, Gopinath K, Gowri S, Karthika V (2015b) Synthesis of cerium oxide nanoparticles using Gloriosa superba L. leaf extract and their structural, optical and antibacterial properties. Mater Sci Eng C Mater Biol Appl 49:408-415

Arunkumar P, Ramaseshan R, Dash S, Basu J, Ravindran TR, Balakumar S, Suresh K (2014) Babu Texturing of pure and doped $\mathrm{CeO}_{2}$ thin films by EBPVD through target engineering. RSC Adv 4:33338-33346

Balakrishnan G, Raghavan CM, Ghosh C, Divakar R, Mohandas E, Song JI, Bae SI, Gyu Kim T (2013) X-ray diffraction, Raman and photoluminescence studies of nanocrystalline cerium oxide thin films. Ceram Int 39:8327-8333

Basavaraj RB, Nagabhushana H, Darshan GP, Sharma SC, Venkatachalaiah K (2017) Ultrasound assisted rare earth doped Wollastonite nanopowders: labeling agent for imaging eccrine latent fingerprints and cheiloscopy applications. J Ind Eng Chem 51:90-105

Binet C, Badri A, Lavalley J-C (1994) A spectroscopic characterization of the reduction of ceria from electronic transitions of intrinsic point defects. J Phys Chem 98:6392-6398

Choi Y, Abernathy H, Chen HT, Lin M, Liu M (2006) Characterization of $\mathrm{O}_{2}-\mathrm{CeO}_{2}$ interactions using in situ Raman spectroscopy and first-principle calculations. Chem Phys Chem 7:1957-1963

Dang F, Kato K, Imai H, Wada S, Haneda H, Kuwabara M (2010) Characteristics of $\mathrm{CeO}_{2}$ nanocubes and related polyhedra prepared by using a liquid-liquid interface. Cryst Growth Des 10:4537-4541

Darshan GP, Premkumar HB, Nagabhushana H, Sharma SC, DarukaPrasad B, Prashantha SC, Basavaraj RB (2016) Superstructures of doped yttrium aluminates for luminescent and advanced forensic investigations. J Alloys Compd 686:577-587

Derakhshandeh PG, Soleimannejad J (2016) Sonochemical synthesis of a new nano-sized cerium (III) supramolecular compound. Precursor for nanoceria. Ultrason Sonochem 31:122-128

Dhanalakshmi M, Nagabhushana H, Darshan GP, Basavaraj RB, Daruka Prasad B (2017) Sonochemically assisted hollow/solid $\mathrm{BaTiO}_{3}: \mathrm{Dy}^{3+}$ microspheres and their applications in effective detection of latent fingerprints and lip prints. J Sci Adv Mater Devices 2:22-33

Guo N, Zheng Y, Jia Y, Qiao H, You H (2012) Warm-white-emitting from $\mathrm{Eu}^{2+} / \mathrm{Mn}^{2+}$-Co doped $\mathrm{Sr}_{3} \mathrm{Lu}\left(\mathrm{PO}_{4}\right)_{3}$ phosphor with tunable color tone and correlated color temperature. J Phys Chem C 116:1329-1334

Huang P, Wu F, Zhu B, Gao X, Zhu H, Yan T, Huang W, Wu S, Song D (2005) $\mathrm{CeO}_{2}$ nanorods and gold nanocrystals supported on $\mathrm{CeO}_{2}$ nanorods as catalyst. J Phys Chem B 109:19169-19174

Jamshidi P, Salavati-Niasari M, Ghanbari D, Shams HR (2013) Synthesis, characterization, photoluminescence and photocatalytic properties of $\mathrm{CeO}_{2}$ nanoparticles by the sonochemical method. J Cluster Sci 24:1151-1162

Jiang D, Zhang M, Li G, Jiang H (2012) Preparation and evaluation of $\mathrm{MnOx}-\mathrm{CeO}_{2}$ nanospheres via a green route. Catal Commun 17:59-63

Jorge AB, Sakatani Y, Boissière C, Laberty-Roberts C, Sauthier G, Fraxedas J, Sanchez C, Fuertes A (2012) Nanocrystalline $\mathrm{N}$-doped ceria porous thin films as efficient visible-active photocatalysts. J Mater Chem 22:3220-3226

Ketzial JJ, Nesaraj AS (2011) Synthesis of $\mathrm{CeO}_{2}$ nanoparticles by chemical precipitation and the effect of a sur-factant on the distribution of particle sizes. J Ceram Proc Res 12:74-79

Khan SB, Faisal M, Rahman MM, Akhtar K, Asiri AM, Khan A, Alamry KA (2013) Effect of particle size on the photocatalytic activity and sensing properties of $\mathrm{CeO}_{2}$ nanoparticles. Int $\mathbf{J}$ Electrochem Sci 8:7284

Khan MM, Ansari SA, Pradhan D, Han DH, Lee J, Cho MH (2014) Defect-induced band gap narrowed $\mathrm{CeO}_{2}$ nanostructures for visible light activities. Ind Eng Chem Res 53:9754-9763

Konysheva E, Francis S, Irvine J (2010) Crystal structure, oxygen nonstoichiometry, and conductivity of mixed ionic-electronic conducting perovskite composites with $\mathrm{CeO}_{2}$. J Electrochem Soc 157:B159-B165

Lee J, Park Y, Joo SW, Sohn Y (2014) Doping-concentration and annealing effects on photoluminescence profile of $\mathrm{Eu}(\mathrm{III})$-doped $\mathrm{CeO}_{2}$ nanorods. Bull Korean Chem Soc 35:3319 
Lehnen T, Schläfer J, Mathur S (2014) Rapid microwave synthesis of $\mathrm{CeO}_{2}$ quantum dots. $\mathrm{Z}$ Anorg Allg Chem 640:819-825

Lei W, Zhang T, Gu L, Liu P, Rodriguez JA, Liu G, Liu M (2015) Surface-structure sensitivity of $\mathrm{CeO}_{2}$ nanocrystals in photocatalysis and enhancing the reactivity with nanogold. ACS Catal 5:4385-4393

Li Z, Li L, Yuan Q, Feng W, Xu J, Sun L, Song W, Yan C (2008) Sustainable and facile route to nearly monodisperse spherical aggregates of $\mathrm{CeO}_{2}$ nanocrystals with ionic liquids and their catalytic activities for $\mathrm{CO}$ oxidation. J Phys Chem $\mathrm{C}$ 112:18405-18411

Li J, Lu G, Li H, Wang Y, Guo Y, Guo Y (2011) Facile synthesis of $3 \mathrm{D}$ flowerlike $\mathrm{CeO}_{2}$ microspheres under mild condition with high catalytic performance for $\mathrm{CO}$ oxidation. J Colloid Interface Sci 360:93-99

Li L, Wang S, Mu G, Yin X, Ou K, Yi L (2015a) A novel violet/blue light-emitting device based on $\mathrm{Ce}_{2} \mathrm{Si}_{2} \mathrm{O}_{7}$. Sci Rep 5:16659. doi:10.1038/srep16659

Li L, Wang H, Zou L, Wang X (2015b) Controllable synthesis, photocatalytic and electrocatalytic properties of $\mathrm{CeO}_{2}$ nanocrystals. RSC Adv 5:41506-41512

Li Z, Chen Y, Xin Y, Zhang Z (2015c) Sensitive electrochemical nonenzymatic glucose sensing based on anodized $\mathrm{CuO}$ nanowires on three-dimensional porous copper foam. Sci Rep 5:16115

Lin Y, Wu Z, Wen J, Poeppelmeier KR, Marks LD (2013) Imaging the atomic surface structures of $\mathrm{CeO}_{2}$ nanoparticles. Nano Lett 14:191-196

Liu IT, Hon MH, Teoh LG (2013) Structure and optical properties of $\mathrm{CeO}_{2}$ nanoparticles synthesized by precipitation. J Electron Mater 42:2536-2541

Lopez H, Mendoza H (2013) Temperature effects on the crystallization and coarsening of nano- $\mathrm{CeO}_{2}$ powders. ISRN Nano Mater 2013:208614. doi:10.1155/2013/208614

Lopez JM, Gilbank AL, Garcia T, Solsona B, Agouram S, TorrenteMurciano L (2015) The prevalence of surface oxygen vacancies over the mobility of bulk oxygen in nanostructured ceria for the total toluene oxidation. Appl Catal B 174:403-412

Luo H, Bos AJ, Dobrowolska A, Dorenbos P (2015) Low-temperature VUV photoluminescence and thermoluminescence of UV excited afterglow phosphor $\mathrm{Sr}_{3} \mathrm{Al}_{\mathrm{x}} \mathrm{Si}_{1-\mathrm{x}} \mathrm{O}_{5}: \mathrm{Ce}^{3+}, \mathrm{Ln}^{3+}(\mathrm{Ln}=\mathrm{Er}$, Nd, Sm, Dy and Tm). Phys Chem Chem Phys 17:15419-15427

Maensiri S, Masingboon C, Laokul P, Jareonboon W, Promarak V, Anderson PL, Seraphin S (2007) Egg white synthesis and photoluminescence of platelike clusters of $\mathrm{CeO}_{2}$ nanoparticles. Cryst Growth Des 7:950-955

Maensiri S, Labuayai S, Laokul P, Klinkaewnarong J, Swatsitang E (2014) Structure and optical properties of $\mathrm{CeO}_{2}$ nanoparticles prepared by using lemongrass plant extract solution. Jpn J Appl Phys 53:06JG14. doi:10.1088/0957-4484/16/9/006

Magesh G, Viswanathan B, Viswanath R, Varadarajan T (2009) Photocatalytic behavior of $\mathrm{CeO}_{2}-\mathrm{TiO}_{2}$ system for the degradation of methylene blue. Indian J Chem Sect A 48:480

Malleshappa J, Nagabhushana H, Sharma SC, Vidya YS, Anantharaju KS, Prashantha SC, DarukaPrasad B, RajaNaika H, Lingaraju K, Surendra B (2015) Leucas aspera mediated multifunctional $\mathrm{CeO}_{2}$ nanoparticles: structural, photoluminescent, photocatalytic and antibacterial properties. Spectrochim Acta Part A 149:452-462

Malleshappa J, Nagabhushana H, DarukaPrasad B, Sharma BS, Vidya YS, Anantharaju KS (2016) Structural, photoluminescence and thermoluminescence properties of $\mathrm{CeO}_{2}$ nanoparticles. Opt Int $\mathrm{J}$ Light Electron Opt 127:855-861

Malleshappaa J, Nagabhushanab H, Sharmac SC, Sunithab DV, Dhananjayad N, Shivakumarae C, Nagabhushana BM (2014) Self propagating combustion synthesis and luminescent properties of nanocrystalline $\mathrm{CeO}_{2}: \mathrm{Tb}^{3+}(1-10 \mathrm{~mol} \%)$ phosphors. J Alloys Compd 590:131-139

Morshed A, Moussa M, Bedair S, Leonard R, Liu S, El-Masry N (1997) Violet/blue emission from epitaxial cerium oxide films on silicon substrates. Appl Phys Lett 70:1647-1649

Periyat P, Laffir F, Tofail S, Magner E (2011) A facile aqueous solgel method for high surface area nanocrystalline $\mathrm{CeO}_{2}$. RSC Adv 1:1794-1798

Sahu HR, Rao GR (2000) Characterization of combustion synthesized zirconia powder by UV-vis, IR and other techniques. Bull Mater Sci 23:349-354

Saif M, Shebl M, Nabeel A, Shokry R, Hafez H, Mbarek A, Damak K, Maalej R, Abdel-Mottaleb M (2015) Novel non-toxic and red luminescent sensor based on $\mathrm{Eu}^{3+}: \mathrm{Y}_{2} \mathrm{Ti}_{2} \mathrm{O}_{7} / \mathrm{SiO}_{2}$ nano-powder for latent fingerprint detection. Sens Actuators B 220:162-170

Sathyamurthy S, Leonard KJ, Dabestani RT, Paranthaman MP (2005) Reverse micellar synthesis of cerium oxide nanoparticles. Nanotechnology 16:1960. doi:10.1088/0957-4484/16/9/089

Sayed FN, Grover V, Dubey KA, Sudarsan V, Tyagi AK (2011) Solid state white light emitting systems based on $\mathrm{CeF}_{3}$ : $\mathrm{RE}^{3+}$ nanoparticles and their composites with polymers. J Colloid Interface Sci 353:445-453

Sharma V, Das A, Kumar V, Ntwaeaborwa O, Swart H (2014) Potential of $\mathrm{Sr}_{4} \mathrm{Al}_{14} \mathrm{O}_{25}: \mathrm{Eu}^{2+}, \mathrm{Dy}^{3+}$ inorganic oxide-based nanophosphor in Latent fingermark detection. J Mater Sci 49:2225-2234

Shivaram M, Nagabhushana H, Sharma SC, Prashantha SC, DarukaPrasad B, Dhananjaya N, HariKrishna R, Nagabhushana BM, Shivakumara C, Chakradhar RPS (2014) Synthesis and luminescence properties of $\mathrm{Sm}^{3+}$ doped $\mathrm{CaTiO}_{3}$ nanophosphor for application in white LED under NUV excitation. Spectrochim Acta Part A 128:891-901

Shrivastava R, Kaur J, Dash M (2015) Studies on white light emission of $\mathrm{Sr}_{2} \mathrm{MgSi}_{2} \mathrm{O}_{7}$ doped with $\mathrm{Dy}^{3+}$ phosphors. Superlattices Microstruct 82:262-268

Sun C, Li H, Zhang H, Wang Z, Chen L (2005) Controlled synthesis of $\mathrm{CeO}_{2}$ nanorods by a solvothermal method. Nanotechnology 16:1454. doi:10.1088/0957-4484/16/9/006

Suresh C, Nagabhushana H, Darshan GP, Basavaraj RB, DarukaPrasad B, Sharma SC, Sateesh MK, ShabaazBegum JP (2017) Lanthanum oxyfluoride nanostructures prepared by modified sonochemical method and their use in the fields of optoelectronics and biotechnology. Arabian J Chem. doi:10.1016/j. arabjc.2017.03.006

Venkatachalaiah K, Nagabhushana H, Darshan GP, Basavaraj RB, DarukaPrasad B (2017) Novel and highly efficient red luminescent sensor based $\mathrm{SiO}_{2} @ \mathrm{Y}_{2} \mathrm{O}_{3}: \mathrm{Eu}^{3+}, \mathrm{M}^{+}\left(\mathrm{M}^{+}=\mathrm{Li}, \mathrm{Na}, \mathrm{K}\right)$ composite core-shell fluorescent markers for latent fingerprint recognition, security ink and solid state lightning applications. Sens Actuators B 251:310-325

Wang G, Mu Q, Chen T, Wang Y (2010) Synthesis, characterization and photoluminescence of $\mathrm{CeO}_{2}$ nanoparticles by a facile method at room temperature. J Alloys Compd 493:202-207

Wang M, Li M, Yang M, Zhang X, Yu A, Zhu Y, Qiu P, Mao C (2015a) NIR-induced highly sensitive detection of latent fingermarks by $\mathrm{NaYF}_{4}: \mathrm{Yb}$, Er upconversion nanoparticles in a dry powder state. Nano Res 8:1800-1810

Wang M, Li M, Yu A, Wu J, Mao C (2015b) Rare earth fluorescent nanomaterials for enhanced development of latent fingerprints. ACS Appl Mater Interfaces 7:28110-28115

Wang M, Zhu Y, Mao C (2015c) Synthesis of NIR-Responsive $\mathrm{NaYF}_{4}$ : Yb, Er upconversion fluorescent nanoparticles using an optimized solvothermal method and their applications in enhanced development of latent fingerprints on various smooth substrates. Langmuir 31:7084-7090 
Weber M (1973) Optical spectra of $\mathrm{Ce}^{3+}$ and $\mathrm{Ce}^{3+}$ sensitized fluorescence in $\mathrm{YAlO}_{3}$. J Appl Phys 44:3205-3208

Wei Y, Li M, Jiao S, Huang Q, Wang G, Fang B (2006) Fabrication of $\mathrm{CeO}_{2}$ nanoparticles modified glassy carbon electrode and its application for electrochemical determination of UA and AA simultaneously. Electrochim Acta 52:766-772

Wetchakun N, Chaiwichain S, Inceesungvorn B, Pingmuang K, Phanichphant S, Minett AI, Chen J (2012) $\mathrm{BiVO}_{4} / \mathrm{CeO}_{2}$ nanocomposites with high visible-light-induced photocatalytic activity. ACS Appl Mater Interfaces 4:3718-3723

Xiaoyuan J, Guanglie L, Renxian Z, Jianxin M, Yu C, Xiaoming Z (2001) Studies of pore structure, temperature-programmed reduction performance, and micro-structure of $\mathrm{CuO} / \mathrm{CeO}_{2}$ catalysts. Appl Surf Sci 173:208-220

Xu B, Zhang Q, Yuan S, Liu S, Zhang M, Ohno T (2017) Synthesis and photocatalytic performance of yttrium-doped $\mathrm{CeO}_{2}$ with a hollow sphere structure. Catal Today 281:135-143
Yan B, Zhu H (2008) Controlled synthesis of $\mathrm{CeO}_{2}$ nanoparticles using novel amphiphilic cerium complex precursors. J Nanopart Res 10:1279-1285

Yuan B, Long Y, Wu L, Liang K, Wen H, Luo S, Huo H, Yang H, Ma J (2016) $\mathrm{TiO}_{2} @ \mathrm{~h}-\mathrm{CeO}_{2}$ : a composite yolk-shell microsphere with enhanced photodegradation activity. Catal Sci Technol 6:421-428

Zhou Y, Rahaman MN (1997) Effect of redox reaction on the sintering behavior of cerium oxide. Acta Mater 45:3635-3639

\section{Publisher's Note}

Springer Nature remains neutral with regard to jurisdictional claims in published maps and institutional affiliations 